\title{
Modeling and Finite Element Analysis Simulation of MEMS Based Acetone Vapor Sensor for Noninvasive Screening of Diabetes
}

\author{
John Ojur Dennis, ${ }^{1}$ Almur Abdelkreem Saeed Rabih, ${ }^{2}$ Mohd Haris Md Khir, ${ }^{2}$ \\ Mawahib Gafare Abdalrahman Ahmed, ${ }^{2}$ and Abdelazez Yousif Ahmed ${ }^{2}$ \\ ${ }^{1}$ Department of Fundamental and Applied Sciences, Universiti Teknologi PETRONAS, Bandar Seri Iskandar, 32610 Perak, Malaysia \\ ${ }^{2}$ Department of Electrical and Electronic Engineering, Universiti Teknologi PETRONAS, Bandar Seri Iskandar, 32610 Perak, Malaysia
}

Correspondence should be addressed to Almur Abdelkreem Saeed Rabih; almurutp@gmail.com

Received 19 January 2016; Revised 31 March 2016; Accepted 17 April 2016

Academic Editor: Hai-Feng Ji

Copyright (C) 2016 John Ojur Dennis et al. This is an open access article distributed under the Creative Commons Attribution License, which permits unrestricted use, distribution, and reproduction in any medium, provided the original work is properly cited.

\begin{abstract}
Diabetes is currently screened invasively by measuring glucose concentration in blood, which is inconvenient. This paper reports a study on modeling and simulation of a CMOS-MEMS sensor for noninvasive screening of diabetes via detection of acetone vapor in exhaled breath (EB). The sensor has two structures: movable (rotor) and fixed (stator) plates. The rotor plate is suspended on top of the stator by support of four flexible beams and maintaining certain selected initial gaps of $5,6,7,8,9,10$, or $11 \mu \mathrm{m}$ to form actuation and sensing parallel plate capacitors. A chitosan polymer of varied thicknesses $(1-20 \mu \mathrm{m})$ is deposited on the rotor plate and modeled as a sensing element for the acetone vapor. The minimum polymer coating thickness required to detect the critical concentration (1.8 ppm) of acetone vapor in the EB of diabetic subjects is found to be $4-7 \mu \mathrm{m}$, depending on the initial gap between the rotor and stator plates. However, to achieve sub-ppm detection limit to sense the acetone vapor concentration $(0.4-1.1 \mathrm{ppm})$ in the EB of healthy people, up to $20 \mu \mathrm{m}$ polymer thickness is coated. The mathematically modeled results were verified using the 2008 CoventorWare simulation software and a good agreement within a 5.3\% error was found between the modeled and the simulated frequencies giving more confidence in the predicted results.
\end{abstract}

\section{Introduction}

Diabetes is a chronic disease caused by deficiency of insulin production or by improper use of the insulin by body tissues. The cause is still unknown. However, genetics, environmental, and habitual factors such as lack of exercise and obesity are believed to play a role. Deficiency of insulin occurs due to the destruction of the pancreatic $\beta$ cells responsible for insulin production by the body immune system, and hence glucose concentration in blood becomes high and it can lead to serious health problems such as blindness, kidney failure, heart diseases, premature death, limb amputation, and gangrene [1]. Diabetes is generally diagnosed invasively by measuring glucose concentration in blood. Thus, breath analysis has been developed as a noninvasive way for diabetes diagnostics [2], by measuring acetone concentration in the breath which relates and reflects ketone bodies in blood plasma, blood acetone levels, and $\beta$-hydroxybutyrate in venous blood. The concentration of acetone in the exhaled breath (EB) of the healthy people is in the range of 0.4$1.1 \mathrm{ppm}$ [3], while in the EB of the diabetic subjects it is reported to be higher than $1.71 \mathrm{ppm}[2,4]$. For this research $1.8 \mathrm{ppm}$ was considered to be the threshold for the diabetic subjects.

Several techniques have been used to detect acetone in exhaled human breath for diabetes diagnostics. The most commonly used methods include gas chromatography (GC) with flame ionization detection (FID), mass spectroscopy (MS), ion mobility spectroscopy (IMS), or combinations like GC-MS, proton transfer reaction-mass spectroscopy (PTRMS), and selected ion flow tube mass spectroscopy (SIFTMS) $[5,6]$. Although the above methods are sensitive, they are costly, heavy, and table top equipment and require longer time for sample preparation [6]. 
TABLE 1: Sensors for acetone vapor detection.

\begin{tabular}{|c|c|c|c|}
\hline The sensor & Working principle & Detection limit (ppm) & Working temperature $\left({ }^{\circ} \mathrm{C}\right)$ \\
\hline Zinc oxide $(\mathrm{ZnO})[41]$ & Resistance change & 1000 & 325 \\
\hline Ferroelectric tungsten trioxide $\left(\varepsilon-\mathrm{WO}_{3}\right)[9]$ & Resistance change & 0.20 & 500 \\
\hline Si-doped epsilon- $\mathrm{WO}_{3}[42]$ & Resistance change & 0.02 & 350 \\
\hline Indium nitride (InN) catalyzed with Pt [7] & Current change & 0.4 & 200 \\
\hline $\begin{array}{l}\text { Tin oxide }\left(\mathrm{SnO}_{2}\right) \text { nanotubes functionalized with } \\
\mathrm{Pt} \text { and } \mathrm{Au}[15]\end{array}$ & Resistance change & 0.10 & 350 \\
\hline $\begin{array}{l}\text { Single-crystalline indium oxide }\left(\operatorname{In}_{2} \mathrm{O}_{3}\right) \\
\text { nanowires [43] }\end{array}$ & Resistance change & 25 & 400 \\
\hline Tin oxide $\left(\mathrm{SnO}_{2}\right)$ fibers catalyzed with Pt [17] & Resistance change & 0.12 & 300 \\
\hline $\begin{array}{l}\text { Nanostructured anatase of titanium oxide } \\
\left(\mathrm{TiO}_{2}\right)[44]\end{array}$ & Resistance change & 1 & 500 \\
\hline Pt-functionalized tungsten oxide $\left(\mathrm{WO}_{3}\right)[4]$ & Resistance change & 0.12 & 300 \\
\hline Sr-doped lanthanum orthoferrite $\left(\mathrm{LaFeO}_{3}\right)[16]$ & Resistance change & 500 & 275 \\
\hline $\begin{array}{l}\text { Tungsten trioxide }\left(\mathrm{WO}_{3}\right) \text { nanofibers } \\
\text { functionalized by } \mathrm{Rh}_{2} \mathrm{O}_{3} \text { nanoparticles [13] }\end{array}$ & Resistance change & 0.10 & 350 \\
\hline $\begin{array}{l}\text { Ferroelectric tungsten trioxide }\left(\varepsilon-\mathrm{WO}_{3}\right) \text { doped } \\
\text { with } \mathrm{Cr}[12]\end{array}$ & Resistance change & 0.20 & 400 \\
\hline Ni-doped zinc oxide $(\mathrm{ZnO})$ nanorods [14] & Resistance change & 100 & Room temperature \\
\hline The proposed MEMS sensor & $\begin{array}{l}\text { Frequency/amplitude } \\
\text { change }\end{array}$ & 0.4 & Room temperature \\
\hline
\end{tabular}

Other methods are used as alternatives to tackle issues related to GC-MS techniques [7]. For instance, laser spectroscopic techniques have been used because of their high sensitivity, selectivity, near real time response, and low cost compared to GC-MS techniques [8]. Electrochemical sensors, surface acoustic wave, quartz microbalance, and chemiresistive sensors (metal oxides and nitrides) like $\mathrm{FeO}_{3}$, $\mathrm{SnO}_{2}, \mathrm{CdO}, \mathrm{WO}_{3}$, and $\mathrm{TiO}_{2}$-doped $\mathrm{ZnO}$ and $\mathrm{InO}_{2}, \mathrm{InN}$, and $\mathrm{LaFeO}_{3}$ were well reported in many works to replace GC-MS techniques [7, 9-12]. Nowadays several noble metals such as platinum $(\mathrm{Pt})$, gold $(\mathrm{Au})$, silver $(\mathrm{Ag})$, palladium $(\mathrm{Pd})$, nickle $(\mathrm{Ni})$, chromium $(\mathrm{Cr})$, strontium $(\mathrm{Sr})$, and rhodium $(\mathrm{Rh})$ have been extensively used by many researchers [4, 7, 13-17] as catalysts to increase the sensitivity and selectivity of the chemiresistive sensors toward acetone vapor detection. Table 1 summarizes some of them.

Doping the chemiresistive films with noble metals enhances the sensitivity of many sensors toward acetone vapor detection. However, as shown in Table 1 some sensors still do not have the desired sensitivity and selectivity to detect the low concentration of acetone vapor in EB [18]. To achieve the best detection limit of the chemiresistive sensors the working temperature is normally high. However, higher working temperatures require higher supplied currents to the heaters which results in higher power consumption. Thus, sensors with working temperature of less than $200^{\circ} \mathrm{C}$ are encouraged to use for better power consumption [19, 20]. Another way to reduce the power consumption of the chemiresistive sensors is to use microheaters fabricated by micromachining technologies [21]. Micromachining of Microelectromechanical Systems (MEMS) devices is known to have the potential to fabricate microheaters that achieves submilliwatt power consumption [22].

MEMS resonators are believed to have very high mass sensitivity due to their small size. In addition, MEMS resonators are based on frequency shift sensing, which is considered as a high accuracy measurement technique [23]. Furthermore, MEMS resonators are coated with a layer specifically selective to the targeted gas and hence it does not require heating power.

There are many techniques to fabricate MEMS resonators. They include PolyMUMPS, MetalMUMPS, Silicon on Insulator (SOI), and Complementary-Metal-Oxide-Semiconductor (CMOS) techniques. Among the various fabricating techniques, CMOS is considered to be the best candidate due to its ability to integrate the circuitry and the sensing transducer in a single chip and also the possibility of batch-fabrication. This results in lower power consumption, reduced cost, better sensitivity, and improved signal to noise ratio [24]. The detection depends on functionalization of these resonators with suitable and sensitive materials for the targeted biomarkers. The functionalized resonator is driven with a known frequency, and when an interaction occurs between the sensitive layer and the targeted biomarker the resonator frequency changes. This change is proportional to the concentration of the biomarker and it has a meaningful value. Chitosan polymer was identified to be a very sensitive polymer to acetone vapor and it was used for the first time to detect acetone vapor concentration in EB [25]. The detection was based on electrochemical technique and hence measurement of the change of electrical properties of the deposited chitosan film when exposed to acetone vapor. It was carried out at room 


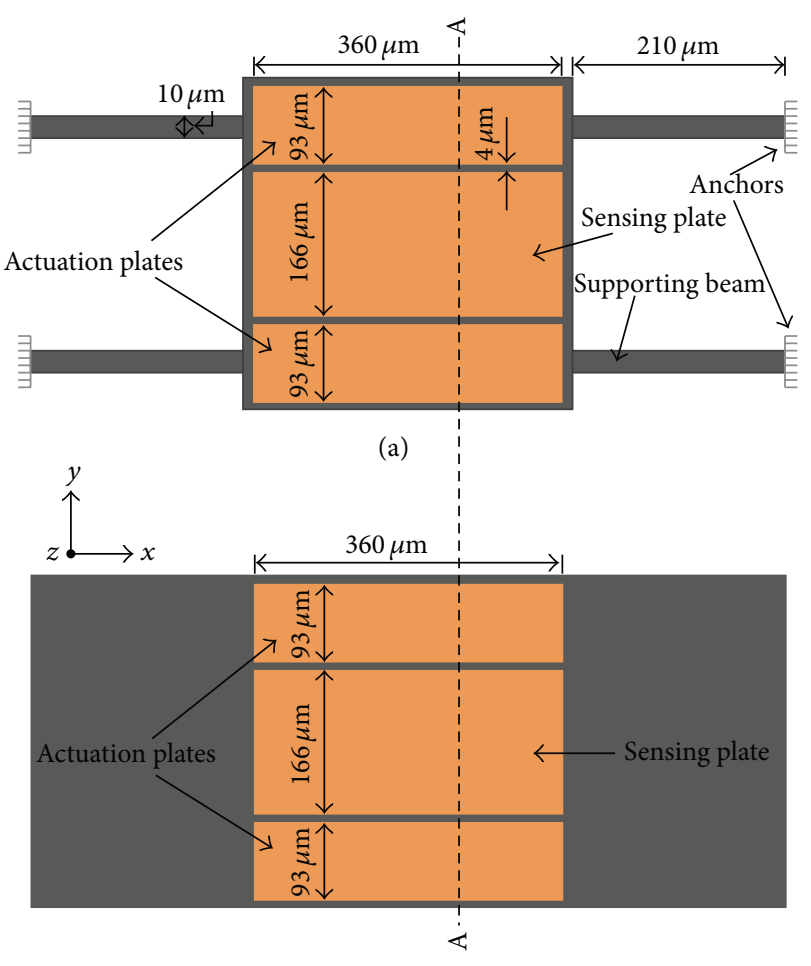

(b)

FIGURE 1: Schematic of the proposed device showing (a) the top rotor and (b) the bottom stator plates with the actuation and sensing parallel plates.

temperature with good response, recovery time, stability, and repeatability. To the best of our knowledge, up to date, there are no reports on detecting acetone vapor in EB for diabetes detection using CMOS-MEMS devices coated with polymers. Thus, this paper proposes a noninvasive and sensitive CMOSMEMS device functionalized by chitosan polymer and based on mass loading and frequency or amplitude shift for the detection of acetone vapor concentration in EB for the purpose of screening diabetes.

\section{Materials and Methods}

2.1. Design of the Sensor Device. The schematic of the modeled device is shown in Figure 1. It consists of two structures that will be bonded together, namely, (a) the movable structure (rotor) and (b) the fixed structure (stator) that will be fabricated using $0.35 \mu \mathrm{m}$ CMOS process technology at MIMOS Berhad company in Malaysia. This technology uses two polysilicon layers, three metal (aluminum) layers, and two vias. Each structure consists of three electrodes made up of the three metal layers connected together by vias to form parallel plate capacitors for actuation and sensing purposes. Two of the capacitors on the sides are used for electrostatic actuation while the capacitor in the center is used for sensing. The rotor is a square plate supported by four identical flexible beams to suspend it on top of the stator and maintain a certain initial gap $\left(z_{0}\right)$ between the plates on rotor and those on the stator.

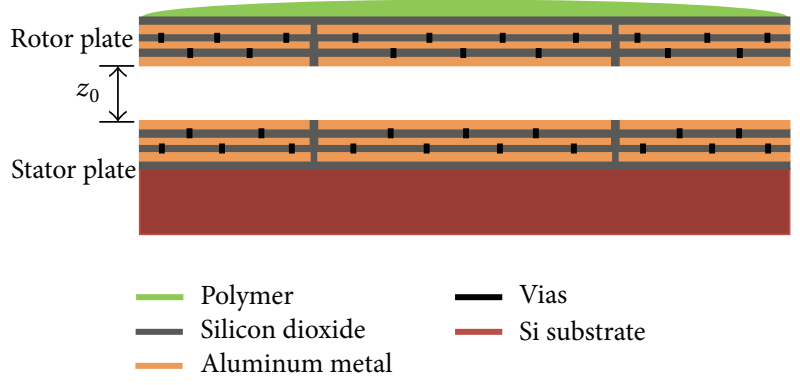

FIGURE 2: Cross section view of the rotor and stator square plates showing the CMOS layers and the silicon substrate underneath the stator plate and the polymer coating on top of the rotor plate.

The rotor plate consists of only the CMOS layers with a total thickness of $6.15 \mu \mathrm{m}$, while the bottom stator structure has a silicon substrate underneath the CMOS layers. Upon the completion of fabrication and releasing of the rotor plate, the device is functionalized by coating it with a sensitive polymer layer on the reverse side of the rotor plate opposite to the actuating and sensing capacitors. Figure 2 shows the cross section view (across $\mathrm{A}-\mathrm{A}$ in Figure 1 ) of the rotor and stator square plates showing the CMOS layers, the silicon substrate underneath the stator plate, and the polymer coating on top of the rotor plate.

2.2. Determination of Resonance Frequency, Mass Sensitivity, and Quality Factor. Due to the vertical movement of the rotor plate toward the stator plate, the device is dominantly affected by only squeeze film damping $b_{\text {sq. }}$. Depending on the value of $b_{\text {sq }}$, the device can be underdamped, overdamped, or critically damped. Only the underdamped devices can be used as resonators for mass sensing applications [26].

Equation (1) is used to find the resonance frequency $f_{r}$ of the resonator $[27,28]$ :

$$
f_{r}=\frac{1}{2 \pi} \sqrt{\frac{k}{\left(m_{\mathrm{eff}}+M_{P}\right)}-\frac{b_{\mathrm{sq}}^{2}}{4\left(m_{\mathrm{eff}}+M_{P}\right)^{2}}},
$$

where $k$ is the spring constant of the flexible beams, $m_{\text {eff }}$ is the total effective mass of the uncoated device, $M_{P}$ is the mass of the sensitive layer, and $b_{\mathrm{sq}}$ is the squeeze film damping. The spring constant of the four beams in the transverse (out of plane) mode is calculated using [29]

$$
k=4 \frac{E_{\mathrm{avg}} w t^{3}}{l^{3}},
$$

where $E_{\mathrm{avg}}$ is the average Young's modulus of the beam's materials, $w, t$, and $l$ are the width, thickness, and length of each beam, and $E_{\text {avg }}$ of the composite layers can be calculated using [30]

$$
E_{\mathrm{avg}}=\frac{\sum E_{i} t_{i}}{t}
$$

where $E_{i}$ and $t_{i}$ are Young's modulus and the thickness of each layer, respectively, and $t$ is the total thickness of the layers. 
TABLE 2: Young's modulus and densities of the CMOS layers.

\begin{tabular}{lcc}
\hline Layer & $\begin{array}{c}\text { Young's modulus } \\
(\mathrm{GPa})\end{array}$ & $\begin{array}{c}\text { Density } \\
\left(\mathrm{kg} / \mathrm{m}^{3}\right)\end{array}$ \\
\hline Substrate (silicon 100$)$ & 169 & 2330 \\
Structure material $\left(\mathrm{SiO}_{2}\right)$ & 73 & 2300 \\
Structure material (aluminum) & 70 & 2700 \\
\hline
\end{tabular}

The effective mass $m_{\text {eff }}$ of the uncoated device is the summation of the effective mass $m_{\text {beff }}$ of the four beams and the static mass $m_{p}$ of the square center plate. Equation (4) is used to find the effective mass of the four fixed-guided supporting beams [31, 32], and the static mass of the center plate is found using

$$
\begin{aligned}
m_{\text {beff }} & =4 \times \frac{13}{35} \rho_{\text {avg }} l w t \\
m_{p} & =\rho_{\text {avg }} A t,
\end{aligned}
$$

where $A$ is the area of the square plate and $\rho_{\text {avg }}$ is the average mass density of the composite layers used, and it is estimated by using [33]

$$
\rho_{\mathrm{avg}}=\frac{\sum \rho_{i} t_{i}}{t}
$$

where $\rho_{i}$ and $t_{i}$ are the density and the thickness of each layer, respectively, and $t$ is the total thickness of the layers. Table 2 shows Young's modulus and densities of the CMOS layers.

The mass $M_{P}$ of the functionalized layer (chitosan polymer) can be calculated using

$$
M_{P}=\rho_{P} A_{P} t_{P},
$$

where $\rho_{P}$ and $t_{P}$ are the density and the thickness of the deposited polymer, respectively, and $A_{P}$ is the deposited area of the square plate.

The squeeze film damping $b_{\text {sq }}$ of the device with the square plate with side length $l_{P}$ can be found using [32]

$$
b_{\mathrm{sq}}=768 \frac{l_{P}^{4} \eta}{z_{0}^{3} \pi^{6}}\left(\frac{2}{\left(4+\left(24 \eta l_{P}^{2} f_{r} / \pi z_{0}^{2} P\right)^{2}\right)}\right),
$$

where $\eta$ is the viscosity of the analyte being detected at a given pressure $P, f_{r}$ is the resonance frequency, and $z_{0}$ is the initial gap between the rotor and stator plates. The ratio of the squeeze film damping to the critical damping was found for the different initial gaps $z_{0}$ of $5,6,7,8,9,10$, and $11 \mu \mathrm{m}$ to determine the condition (underdamping, critical damping, or overdamping) of the resonator. The critical damping is found by [34]

$$
b_{c}=4 \pi f_{r}\left(m_{\mathrm{eff}}+M_{P}\right) \text {. }
$$

The device was found to be overdamped for $5 \mu \mathrm{m}$ initial gap with damping ratio 1.4-1.2 and underdamped for the initial gaps of $6,7,8,9,10$, and $11 \mu \mathrm{m}$ with damping ratios $0.8-0.7,0.5-0.45,0.35-0.3,0.25-0.2,0.18-0.15$, and $0.13-0.12$, respectively, in the polymer coating thickness range of 1$10 \mu \mathrm{m}$. It is clear that for gaps of $5 \mu \mathrm{m}$ and $6 \mu \mathrm{m}$ the device will not behave as a resonator due to the very large damping ratios.

The mass sensitivity $S_{m}$ of the device determines its ability of detecting small mass changes. The higher the mass sensitivity is, the better the device will be, while low mass sensitivity gives poor performance. By taking the derivative of (1), the mass sensitivity of the device is expressed as shown in

$$
S_{m}=\frac{\partial f_{r}}{\partial\left(m_{\mathrm{eff}}+M_{P}\right)}=-\frac{M_{T}\left(b_{\mathrm{sq}}^{2}-2 k M_{T}\right)}{4 \pi M_{T}^{3} \sqrt{4 k M_{T}-b_{\mathrm{sq}}^{2}}},
$$

where $M_{T}$ is the total mass of the coated device, $M_{T}=m_{\mathrm{eff}}+$ $M_{P}$.

The quality factor $Q$ affects the resolution of the device. The higher the quality factor is, the narrower the bandwidth will be and the better the resolution will be for the given mass sensitivity [35]. As a result a high quality factor gives better signal to noise ratio [36]; hence it will enhance the performance of the device. $Q$ is inversely proportional to the damping of the device as shown by [34]

$$
Q=\frac{2 \pi f_{r}\left(m_{\mathrm{eff}}+M_{P}\right)}{b_{\mathrm{sq}}} .
$$

2.3. Sensor Functionalization, Concentration Sensitivity, and Frequency Shift. The absorbed/adsorbed mass $M_{a}$ of the acetone vapor by the chitosan polymer depends on three parameters. They are the partition coefficient $K$ of the acetone vapor-chitosan polymer interface, the volume $V_{P}$ of the deposited polymer, and the concentration $C_{g}$ of the acetone vapor in the ambient air as given by

$$
M_{a}=K V_{P} C_{g},
$$

where $K$ determines the selectivity of the chitosan polymer to the acetone vapor concentration being detected. It is defined as the ratio of the acetone vapor concentration $C_{g}$ in the ambient air to its concentration $C_{P}$ absorbed by the chitosan polymer as given in (13). $K$ has a range of 100-10,000 for specific analyte-polymer interactions [37]

$$
K=\frac{C_{P}}{C_{g}} .
$$

The absorbed/adsorbed mass $M_{a}$ by the sensitive layer increases the mass of the device, and therefore the resonance frequency $f_{r}$ and the maximum displacement will decrease. The amount of change in the resonance frequency or the displacement depends on $M_{a}$, which is controlled by the three aforementioned parameters. Equation (14) is used to find the change in the resonance frequency of the device due to absorption/adsorption of $M_{a}$ by the polymer:

$$
=\frac{1}{2 \pi} \sqrt{\frac{k}{\left(m_{\mathrm{eff}}+M_{P}+M_{a}\right)}-\frac{b_{\mathrm{sq}}^{2}}{4\left(m_{\mathrm{eff}}+M_{P}+M_{a}\right)^{2}}},
$$


where $f_{1}$ is the change in the resonance frequency $f_{r}$ of the device due to $M_{a}$. The resonance frequency shift $\Delta f$ is found by subtracting $f_{1}$ from $f_{r}$.

The vapor concentration sensitivity $S_{g}$ determines the ability of the device to detect small changes of concentrations of the analyte in the ambient environment. It is defined as the change in the resonance frequency due to the change of the analyte vapor concentration as shown by

$$
S_{g}=\frac{\Delta f_{r}}{\Delta C_{g}}=\frac{\Delta f_{r}}{\Delta\left(m_{\mathrm{eff}}+M_{P}\right)} \frac{\Delta\left(m_{\mathrm{eff}}+M_{P}\right)}{\Delta C_{g}} .
$$

Equation (15) gives the concentration sensitivity in $\mathrm{Hz} / \mathrm{g} / \mathrm{m}^{3}$. To convert it to the widely accepted unit of $\mathrm{Hz} / \mathrm{ppm}$ (16) is used [24]:

$$
S_{g}=\frac{M_{T}\left(b_{\mathrm{sq}}^{2}-2 k M_{T}\right)}{4 \pi M_{T}^{3} \sqrt{4 k M_{T}-b_{\mathrm{sq}}^{2}}} K V_{P} \frac{W P}{R T \times 10^{6}},
$$

where $W$ is the molecular weight of the analyte in $\mathrm{g} / \mathrm{mol}, P$ is the partial pressure (in Pascal) of the analyte at the given temperature $T$ (in Kelvin), and $R$ is the ideal gas constant having the value of $8.3145 \mathrm{~J} \cdot \mathrm{mol}^{-1} \mathrm{~K}^{-1}$.

The limit of detection determines the minimum amount of the analyte that the device is capable of detecting and it depends on the minimum frequency shift detected (resolution) by the frequency measurement instrument. Equation (17) can be used to calculate the minimum detectable concentration (in ppm) of the analyte:

$$
C_{g \min }=\frac{\Delta f_{r}\left(4 \pi M_{T}^{3} \sqrt{4 k M_{T}-b_{\mathrm{sq}}^{2}}\right)}{K V_{P} M_{T}\left(b_{\mathrm{sq}}^{2}-2 k M_{T}\right)} \frac{R T \times 10^{6}}{W P} .
$$

2.4. Maximum Displacement Amplitude. Maximum displacements of the rotor plate due to the electrostatic actuation force $F_{e}$ are modeled using [38]

$$
z=\frac{F_{e}}{M_{T} \sqrt{\left(\left(\omega_{n}^{2}-\omega^{2}\right)^{2}+\left(2 \xi \omega_{n} \omega\right)^{2}\right)}},
$$

where $z$ is the resulting displacement amplitude, $M_{T}$ is the total mass of the coated resonator, $\omega_{n}$ is the natural angular frequency of the device, $\omega$ is the angular frequency of the driving force, and $\xi$ is the damping ratio.

The electrostatic force $F_{e}$ depends on the voltage applied between the rotor and stator actuation plates. The actuation voltage is limited by the pull-in voltage (maximum voltage required to cause the rotor plates to collide with the stator plates) for each given initial gap. The pull-in voltage depends on the stiffness constant of the beams $(k)$ and the initial gap as shown by [24]

$$
V_{m}=\sqrt{\frac{8 k z_{0}^{3}}{27 \varepsilon_{0} A_{a}}}
$$

where $V_{m}$ is the pull-in voltage, $k$ is the stiffness constant, $z_{0}$ is the initial gap, $\varepsilon_{0}$ is the permittivity of free space $(8.85 \times$ $\left.10^{-12} \mathrm{~F} / \mathrm{m}\right)$, and $A_{a}$ is the total area of the actuation plates. It was found that $V_{m}$ is $67.2,88.3,111.3,136.0,162.3,190.1$, and $219.54 \mathrm{~V}$ for the gaps $5,6,7,8,9,10$, and $11 \mu \mathrm{m}$, respectively. Actuation voltages should be far smaller than those pull-in values to avoid the plates collision. Equation (20) is used to calculate the electrostatic forces [24]:

$$
F_{e}=\frac{1}{2} \frac{\varepsilon_{0} A V^{2}}{\left(z_{0}+z\right)^{2}}
$$

where $F_{e}$ is the electrostatic force, $V$ is the applied voltage, and $z$ is the plate displacement.

As indicated earlier the device cannot be used as a resonator for the $5 \mu \mathrm{m}$ and $6 \mu \mathrm{m}$ because there will not be any peak in the displacement response to detect. Hence, the principle of the resonance frequency shift detection cannot be applied for these two gaps. The resonance frequency shift detection relies on the detection of change in the resonance frequency which corresponds to the maximum peak amplitude before and after the additional mass loading. Thus, a study of amplitude change is also proposed and investigated in addition to the resonance frequency change to accommodate $5 \mu \mathrm{m}$ and $6 \mu \mathrm{m}$ gaps. From (18) the mass sensitivity picometer/pictogram ( $\mathrm{pm} / \mathrm{pg}$ ) with regard to displacement change can be found by taking the derivative of the amplitude as in

$$
\frac{\Delta z}{\Delta M_{T}}=-\frac{F_{e}}{M_{T}^{2} \sqrt{\left(\left(\omega_{n}^{2}-\omega^{2}\right)^{2}+\left(2 \xi \omega_{n} \omega\right)^{2}\right)}}=-\frac{z}{M_{T}} .
$$

The mass of the coated device changes due to the additional mass of the targeted analyte. To find the vapor concentration sensitivity $(\mu \mathrm{m} / \mathrm{ppm})$ of the device (22) is used:

$$
\frac{\Delta z}{\Delta C_{g}}=\frac{\Delta z}{\Delta M_{T}} \frac{\Delta M_{T}}{\Delta C_{g}}=-\frac{z}{M_{T}} K V_{P} \frac{W P}{R T \times 10^{6}} .
$$

The change in the amplitude can be applied for all the gaps due to the fact that adding extra mass to a device driven with a constant frequency and force will lead to a decrease in the displacement amplitude as shown in (18).

\section{Results}

3.1. Modeling. The performance of this device was modeled by functionalizing it with a chitosan polymer as a sensitive layer to detect acetone vapor in exhaled breath down to $1.8 \mathrm{ppm}$ (the threshold for diabetes). It was reported that the density and Young's modulus of chitosan are less than $1000 \mathrm{~kg} / \mathrm{m}^{3}$ and equal to $12 \mathrm{MPa}$ [39], respectively, while Rout [40] stated that the density of chitosan is $390 \mathrm{~kg} / \mathrm{m}^{3}$. For this preliminary work the density was taken to be $500 \mathrm{~kg} / \mathrm{m}^{3}$, Young's modulus as $12 \mathrm{MPa}$, and the partition coefficient of the acetone-chitosan combination as 100. Chitosan is coated on the back side of the rotor plate on the opposite to that containing the capacitor electrodes. The thickness of the coated chitosan polymer was varied from $1 \mu \mathrm{m}$ to $10 \mu \mathrm{m}$ with fixed radius of $188 \mu \mathrm{m}$ to study the effect of the variation 


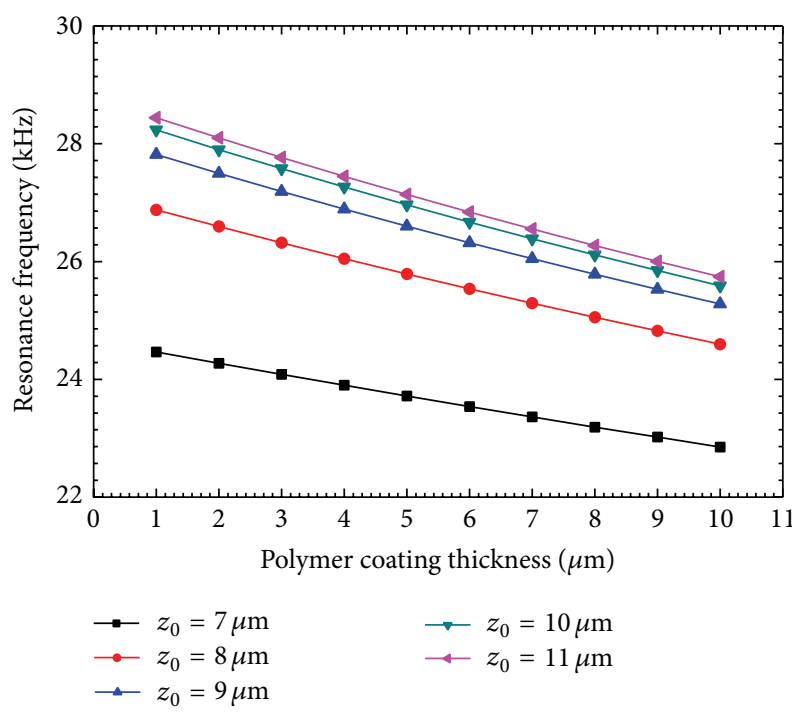

(a)

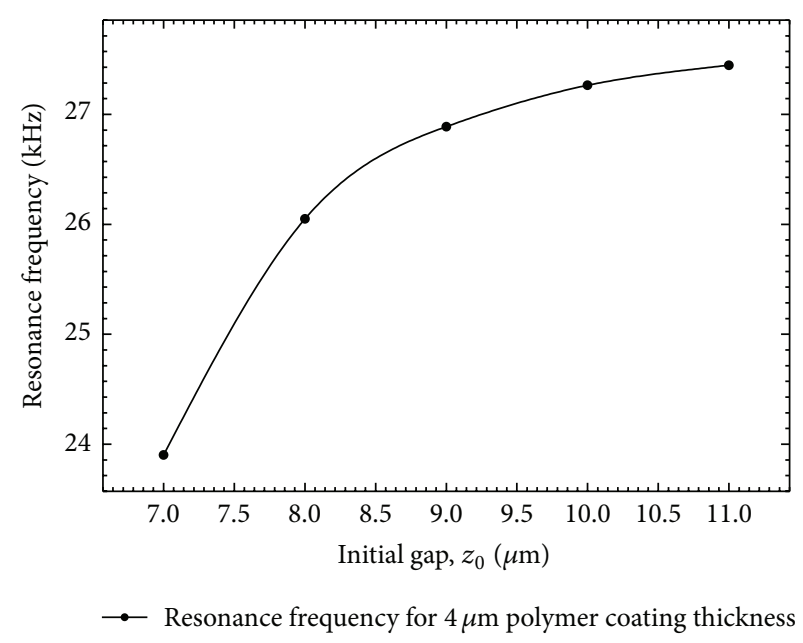

(b)

FIGURE 3: Plot of the resonance frequency of the device (a) versus polymer coating thickness at different initial gaps and (b) versus initial gap for a $4 \mu \mathrm{m}$ polymer coating thickness.

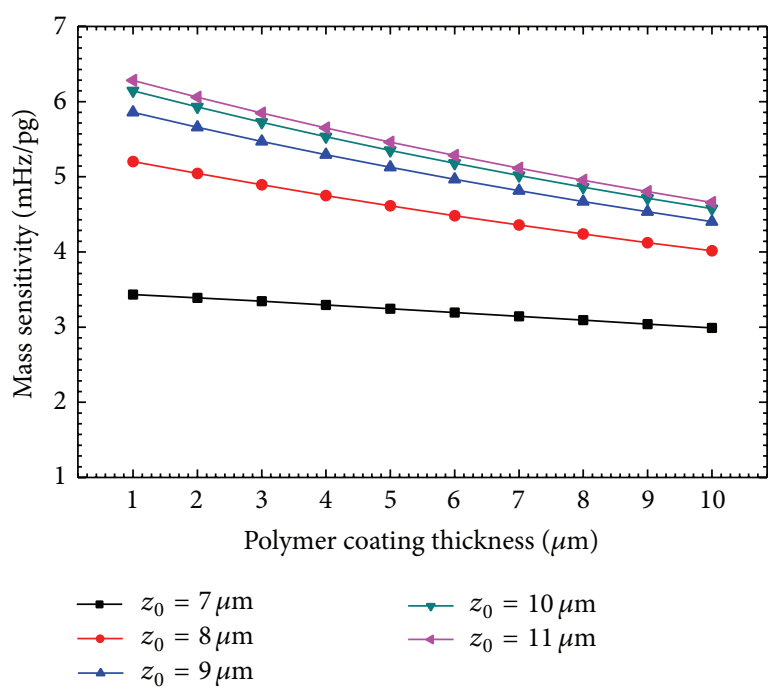

(a)

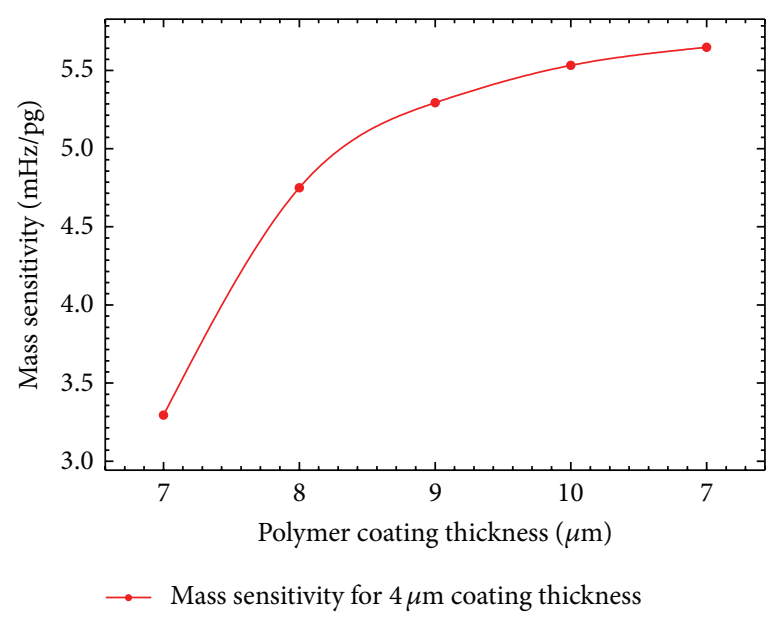

(b)

FIGURE 4: Mass sensitivity of the device (a) versus polymer coating thickness at different initial gaps and (b) versus initial gap for a $4 \mu \mathrm{m}$ polymer coating thickness.

of the coating thickness on the performance of the device. Equations (1), (10), (11), (16), and (17) were used to calculate $f_{r}, S_{m}, Q, S_{g}$, and $C_{\min }$, respectively, of the device at different gaps $z_{0}$ of $7,8,9,10$, and $11 \mu \mathrm{m}$ between the rotor and stator plates and for different polymer thicknesses from 1 to $10 \mu \mathrm{m}$. The gaps of $5 \mu \mathrm{m}$ and $6 \mu \mathrm{m}$ were excluded from this analysis due to the large damping which prevent the device from oscillating. Figures 3, 4, 5, 6, and 7 show the modeled values of $f_{r}, S_{m}, S_{g}, Q$, and $C_{\min }$, respectively.

The resonance frequency of the device decreases by increasing the polymer thickness and increases by increasing the initial gap between the rotor and stator plates. Increasing the polymer thickness leads to the increasing of polymer mass $M_{P}$ which is inversely proportional to the resonance frequency as given in (1), whereas the resonance frequency increases when the initial gap increases due to the squeeze film damping decrease.

Figure 3(a) shows that for the $7 \mu \mathrm{m}$ initial gap the resonance frequency decreases from $24.464 \mathrm{kHz}$ at $1 \mu \mathrm{m}$ polymer coating thickness to $22.851 \mathrm{kHz}$ at the $10 \mu \mathrm{m}$ polymer coating. The highest resonance frequency was found to be for the highest initial gap $11 \mu \mathrm{m}$, and it was found to decrease from $28.440 \mathrm{kHz}$ at $1 \mu \mathrm{m}$ polymer coating thickness to $25.740 \mathrm{kHz}$ at the $10 \mu \mathrm{m}$ polymer coating. The rest of the initial gaps $(8,9$, 


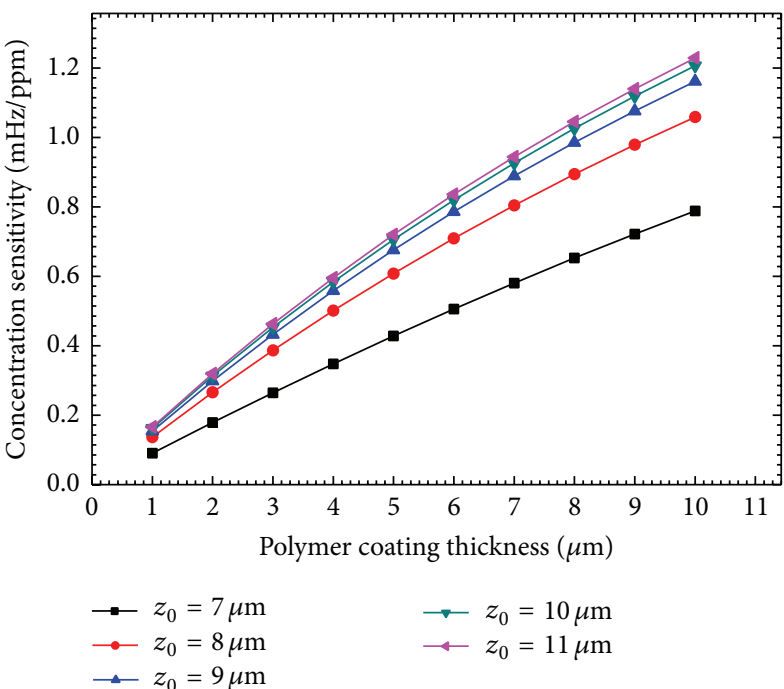

(a)

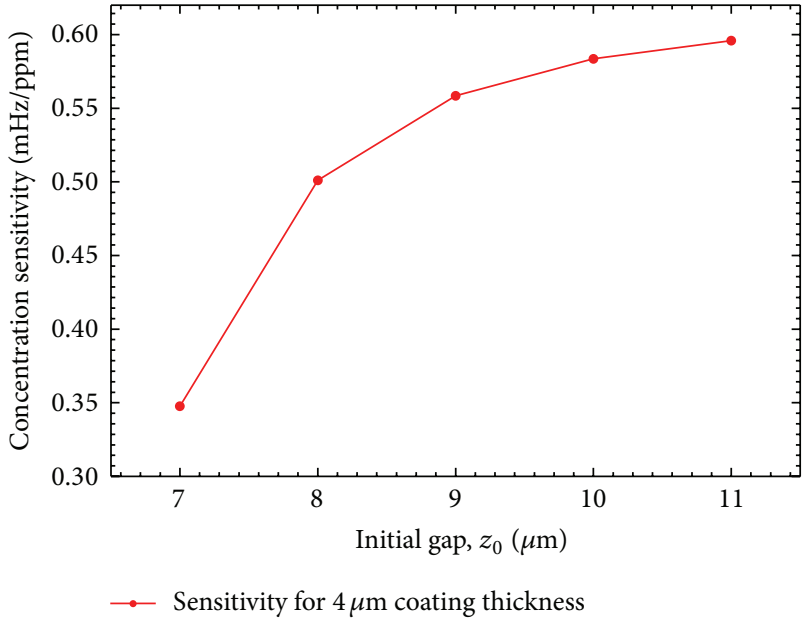

(b)

FIGURE 5: Vapor concentration sensitivity (a) versus polymer coating thickness at different initial gaps and (b) versus initial gap for a $4 \mu \mathrm{m}$ polymer coating thickness.

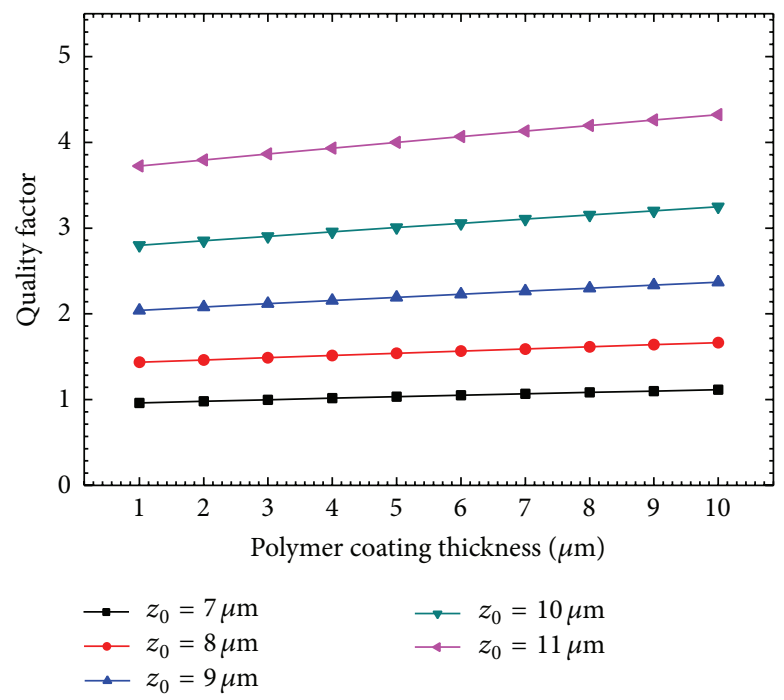

(a)

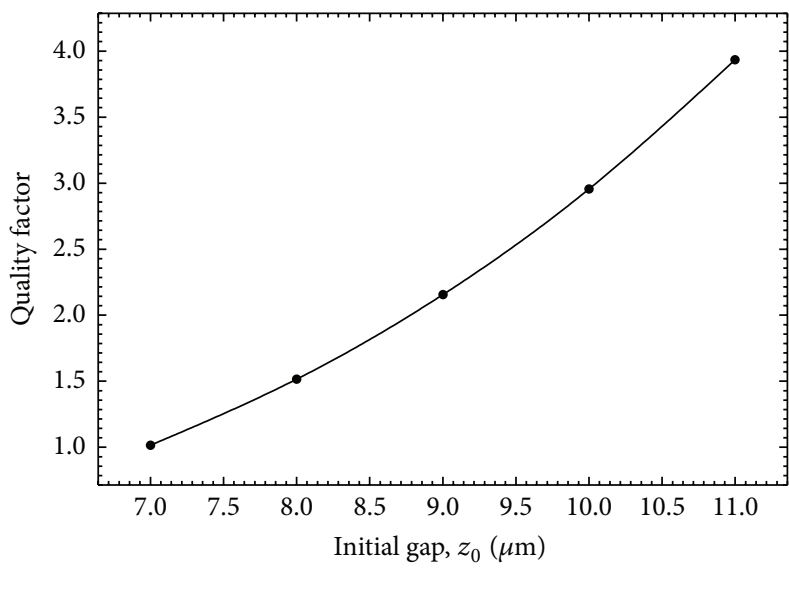

$\rightarrow$ Quality factor for $4 \mu \mathrm{m}$ coating thickness

(b)

FIGURE 6: Quality factor (a) versus polymer coating thickness at different initial gaps and (b) versus initial gap for a $4 \mu \mathrm{m}$ polymer coating thickness.

and $10 \mu \mathrm{m}$ ) have resonance frequencies higher than those of the $7 \mu \mathrm{m}$ gap and less of those of the $11 \mu \mathrm{m}$ gap as shown by Figure 3(b).

Increasing the polymer thickness was found to decrease the mass sensitivity of the device for all the gaps due to the increase of the device total mass as shown in Figure 4(a). The mass sensitivity is inversely proportional to the device mass and linearly proportional to the resonance frequency (10). The larger initial gaps give better mass sensitivity when the coating thickness increases due to the smaller damping.

The mass sensitivity follows the frequency. Thus, for the smaller polymer coating thicknesses the mass sensitivity is higher for all the gaps compared to the higher polymer coating thickness. As shown in Figure 4(a) the mass sensitivity decreases from $3.433 \mathrm{mHz} / \mathrm{pg}$ at $1 \mu \mathrm{m}$ polymer coating thickness to $2.99 \mathrm{mHz} / \mathrm{pg}$ at $10 \mu \mathrm{m}$ polymer coating thickness for the $7 \mu \mathrm{m}$ initial gap, while for the highest given gap $(11 \mu \mathrm{m})$ the mass sensitivity was found to decrease from $6.28 \mathrm{mHz} / \mathrm{pg}$ at $1 \mu \mathrm{m}$ polymer coating thickness to $4.66 \mathrm{mHz} / \mathrm{pg}$ at the $10 \mu \mathrm{m}$ polymer coating thicknesses. As can be observed in Figure $4(\mathrm{~b})$ the rest of the gaps $(8,9$, and $10 \mu \mathrm{m})$ have mass sensitivities less than that of the $11 \mu \mathrm{m}$ initial gap and higher than that of the $7 \mu \mathrm{m}$ initial gap.

Figure 5 shows the vapor concentration sensitivity versus the coating thickness and the initial gap between the stator and the rotor. It is clear that the vapor concentration 


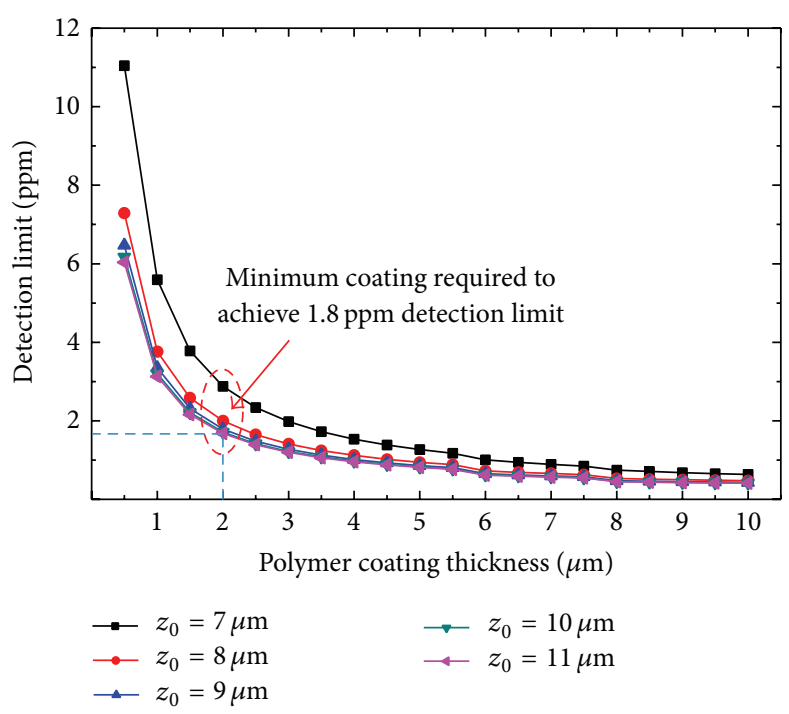

(a)

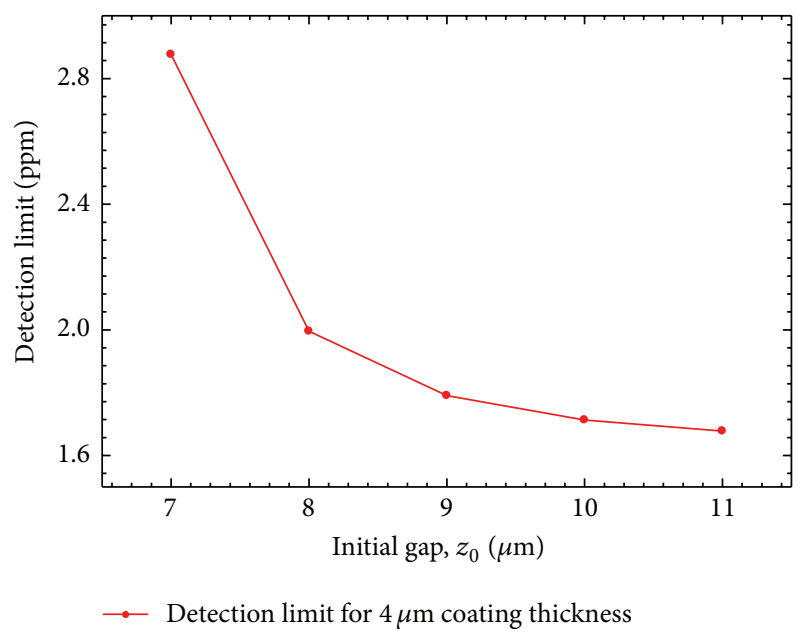

(b)

FIGURE 7: Detection limit (a) versus polymer coating thickness at different initial gaps and (b) versus initial gap for a $4 \mu \mathrm{m}$ polymer coating thickness.

sensitivity increases with increasing the polymer thickness for all the given gaps as shown by Figure 5(a). The least vapor concentration sensitivity was found to be for the least initial gap $(7 \mu \mathrm{m})$ in a range between $0.091 \mathrm{mHz} / \mathrm{ppm}$ at $1 \mu \mathrm{m}$ polymer coating thickness and $0.79 \mathrm{mHz} / \mathrm{ppm}$ at $10 \mu \mathrm{m}$ polymer coating thickness. The highest vapor concentration sensitivity was observed for the $11 \mu \mathrm{m}$ initial gap and it was found to increase from $0.17 \mathrm{mHz} / \mathrm{ppm}$ at $1 \mu \mathrm{m}$ polymer coating thickness to $1.23 \mathrm{mHz} / \mathrm{ppm}$ at $10 \mu \mathrm{m}$ polymer coating thickness. Figure 5(b) shows that the vapor concentration sensitivity increases with increasing the initial gap for a given coating thickness.

The vapor concentration sensitivity depends on the mass sensitivity as shown by (16). For the small coating thicknesses (less than $3 \mu \mathrm{m}$ ) there was no noticeable change in the vapor concentration sensitivity for the different initial gaps. However, as the coating thickness increases from $4 \mu \mathrm{m}$ to $10 \mu \mathrm{m}$ it is clear that the larger gaps are better and give higher vapor concentration sensitivity. The increase in the coating thickness increases the polymer volume which causees the vapor concentration sensitivity to increase. Larger volume means larger polymer surfaces to accommodate bigger amount of the targeted analytes; hence the concentration sensitivity increases.

Figure 6 shows the quality factor $(Q)$ versus the coating thickness and the initial gap between the stator and the rotor plates. The polymer thickness does not significantly affect the quality factor as shown by Figure 6(a). The lowest quality factor was observed for the initial gap of $7 \mu \mathrm{m}$ and it was found to slightly increase from 0.96 at $1 \mu \mathrm{m}$ polymer coating thickness to 1.12 at $10 \mu \mathrm{m}$ polymer coating thickness, while the highest quality factor was found to be for the $11 \mu \mathrm{m}$ initial gap and it increases from 3.72 at $1 \mu \mathrm{m}$ polymer coating thickness to 4.32 at $10 \mu \mathrm{m}$ polymer coating thickness. Figure 6(b) shows that for the given polymer coating thickness the larger gaps give higher quality factor compared to the smaller gaps. Quality factor is inversely proportional to the damping ratio which decreases when the gap is increased.

Figure 7 shows the plot of the detection limit versus the polymer coating and the initial gaps between the rotor and stator plates. As the polymer coating is increased the detection limit of the device is decreased which improves the device performance.

Lower limit means the device is able to detect smaller vapor concentrations. The lower limit of the acetone vapor concentration in the exhaled breath of the diabetic subjects is above $1.71 \mathrm{ppm}$ as mentioned in the literature. Hence the selected coating thickness should be large enough so that the resonator is capable of detecting down to that threshold. It is clear that coating thickness and also the initial gap between the rotor and stator plates affect the performance of the device. Figure 7 (a) shows that for smaller polymer coating thicknesses the limit of detection is very much affected by the polymer coating thickness. It was found to decrease from $11.04 \mathrm{ppm}$ at $1 \mu \mathrm{m}$ polymer coating thickness to $1.27 \mathrm{ppm}$ at $10 \mu \mathrm{m}$ polymer coating thickness for the $7 \mu \mathrm{m}$ initial gap. For the $11 \mu \mathrm{m}$ initial gap it was found to decrease from $6.03 \mathrm{ppm}$ at $1 \mu \mathrm{m}$ polymer coating thickness to $0.81 \mathrm{ppm}$ at $10 \mu \mathrm{m}$ polymer coating thickness. It is clear that, to achieve the minimum detectable concentration of $1.8 \mathrm{ppm}$ acetone vapor in the exhaled breath, minimum coating thickness of $4 \mu \mathrm{m}$ chitosan polymer on the rotor plate is needed according to Figure 7(a) for the initial gaps of 9,10 , and $11 \mu \mathrm{m}$ between the stator and rotor plates. However, to achieve the same threshold for the initial gaps of $7 \mu \mathrm{m}$ and $8 \mu \mathrm{m}$ gaps between the rotor and stator plates, at least $5 \mu \mathrm{m}$ and $7 \mu \mathrm{m}$ coating thicknesses, respectively, are required as shown in Figure 7(a). Figure 7(b) shows that higher gaps are better to achieve lower limit of detection compared to the smaller gaps due to the high squeeze film damping of the smaller gaps. 


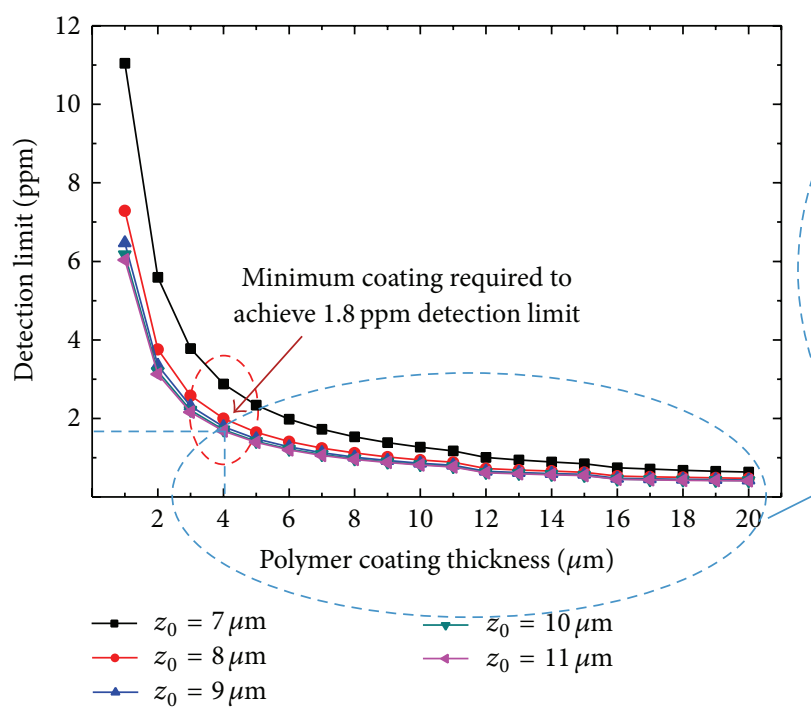

(a)

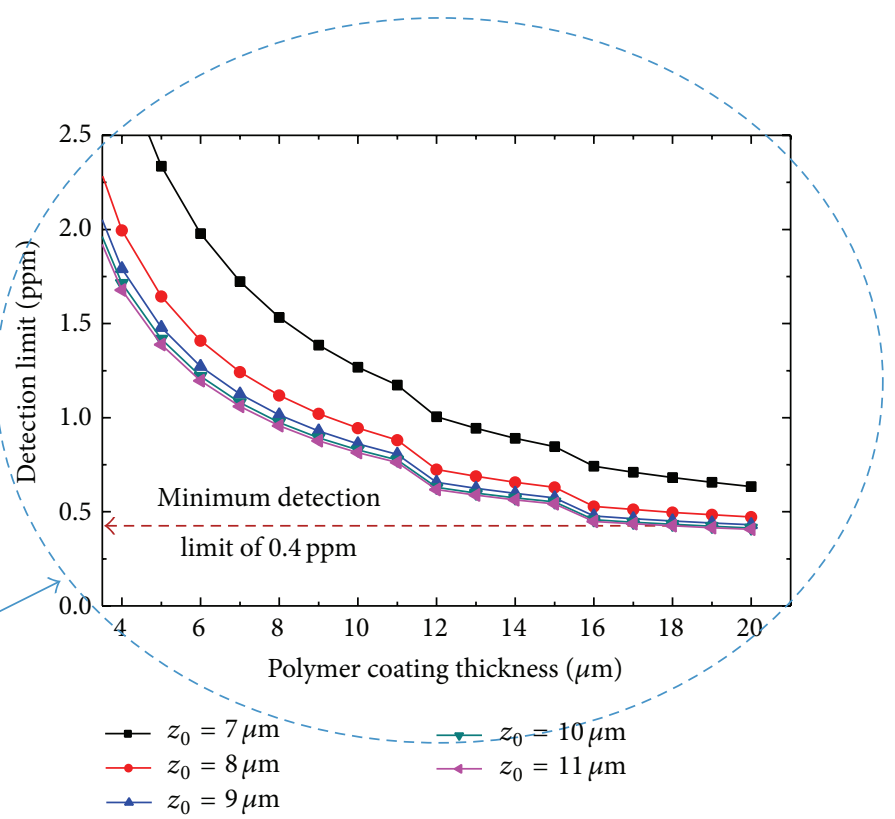

(b)

FIGURE 8: Detection limit (a) for 1-20 $\mu \mathrm{m}$ polymer coating thickness at different initial gaps and (b) lowest detection limit of $0.4 \mathrm{ppm}$ at $4 \mu \mathrm{m}$ coating.

The acetone concentration in the exhaled breath of healthy subjects was reported to be in the range of $0.4-1.1 \mathrm{ppm}$ [3]. To reach sub-ppm detection limit the thickness of the coated polymer (chitosan) is increased to $20 \mu \mathrm{m}$ as shown in Figure 8.

As shown in Figure 8(a), by increasing the polymer coating thickness to more than $10 \mu \mathrm{m}$, sub-ppm detection limit is achieved for all the initial gaps between the rotor and stator plates. Figure 8 (b) depicts that the minimum detection limit required to sense the minimum concentration of acetone in the breath of healthy subjects $(0.4 \mathrm{ppm})$ [3] is achieved at $20 \mu \mathrm{m}$ polymer coating thickness.

3.2. Finite Element Analysis Simulation of the Sensor. Finite Element Analysis (FEA) is used in simulations to study and predict the behaviour of microelectromechanical devices when they are exposed to forces, heat, fluid flow, and so forth. Most of the computer aided design (CAD) systems use FEA for their analysis to find approximate solutions to their problems, and CoventorWare is an example of those systems.

3.2.1. Resonance Frequency. The device with the same dimensions and properties given in the modeling part was simulated using 2008 CoventorWare software for the same initial gap distances $(5,6,7,8,9,10$, and $11 \mu \mathrm{m})$ between the stator and the rotor plates. The thickness of the polymer coating was fixed to $4 \mu \mathrm{m}$ for the reason discussed in the modeling part, and the radius of the polymer coating was $188 \mu \mathrm{m}$. The designer tool of the CoventorWare 2008 was used to create the device. The design steps involve inserting the properties given in Table 1 into the material properties data base of the CoventorWare software, writing the process flow into the
TABLE 3: Modeled and simulated damped natural frequencies.

\begin{tabular}{lccc}
\hline $\begin{array}{l}\text { Gap distance Modeled frequency } \\
(\mu \mathrm{m})\end{array}$ & $\begin{array}{c}\text { Simulated } \\
\text { frequency }(\mathrm{kHz})\end{array}$ & Error\% \\
\hline 7 & 23.901 & 25.168 & 5.302 \\
8 & 26.050 & 25.296 & 2.893 \\
9 & 26.889 & 25.857 & 3.839 \\
10 & 27.264 & 25.915 & 4.951 \\
11 & 27.448 & 26.475 & 3.54 \\
\hline
\end{tabular}

process editor, drawing the $2 \mathrm{D}$ layout by the layout editor, and then finally creating the $3 \mathrm{D}$ structure and meshing the model. The constructed 3D model is shown in Figure 9(a), while the meshed model is given in Figure 9(b). The 3D meshed structure was analyzed and solved using analyzer tool of the CoventorWare 2008 to determine the resonator frequency for the given gaps. Boundary conditions were set by fixing the beams of the resonator at the anchor points shown in Figure 9(a). The numerically calculated damping and force loads were used in the simulation. Figure 10 shows the simulated resonance frequencies of the device for the gaps (a) $8 \mu \mathrm{m}$, (b) $9 \mu \mathrm{m}$, (c) $10 \mu \mathrm{m}$, and (d) $11 \mu \mathrm{m}$.

Table 3 shows the comparison of the simulated frequencies with their corresponding modeled values. As the gap distance increases the frequency also increased due to the decrease in air damping. The percentage difference between modeled and simulated frequencies is $5.3 \%$ for the gap of $7 \mu \mathrm{m}$ and it is less than $5 \%$ for the higher gaps.

3.2.2. Maximum Displacement Amplitude. To study the maximum displacement of the rotor plate for the different gaps 


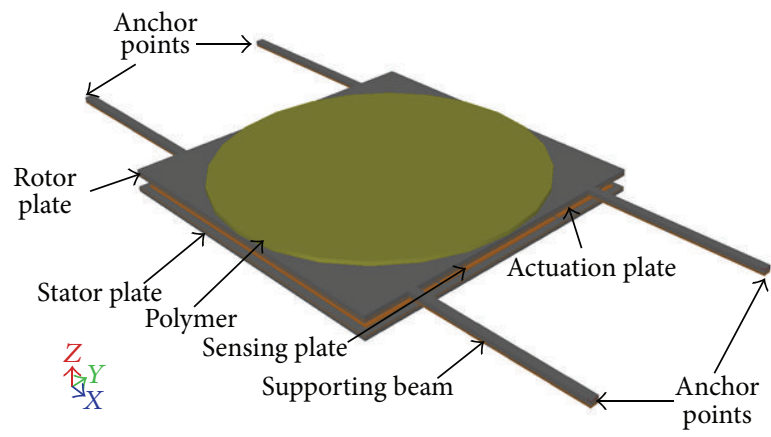

(a)

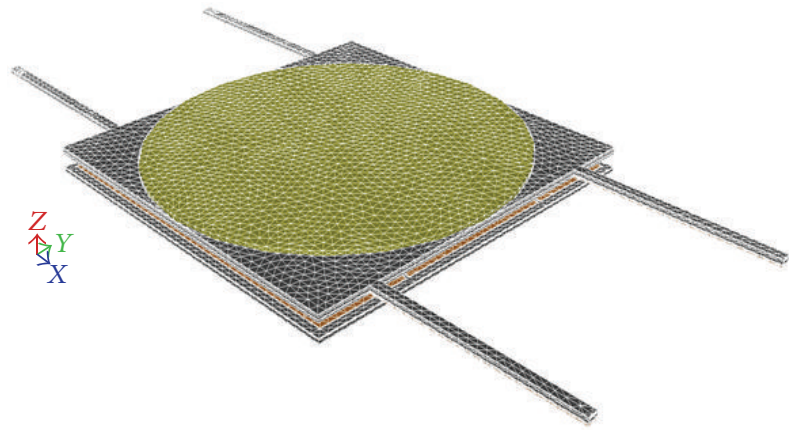

(b)

Figure 9: (a) The 3D model and (b) the meshed model.

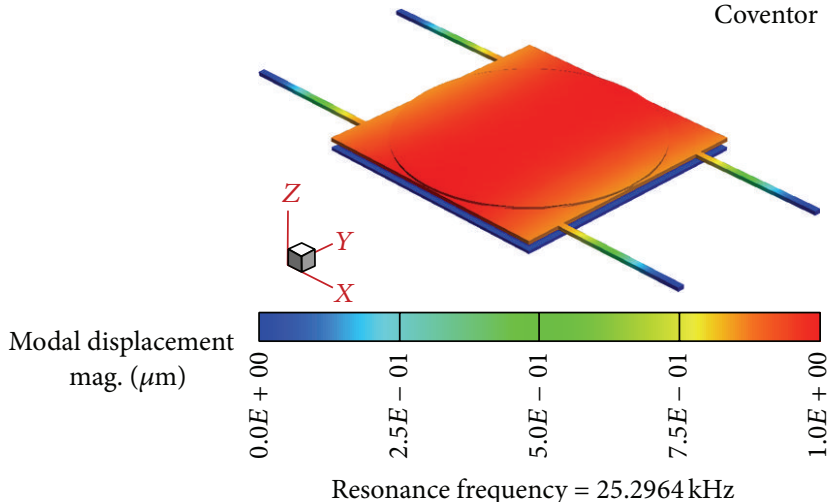

(a)

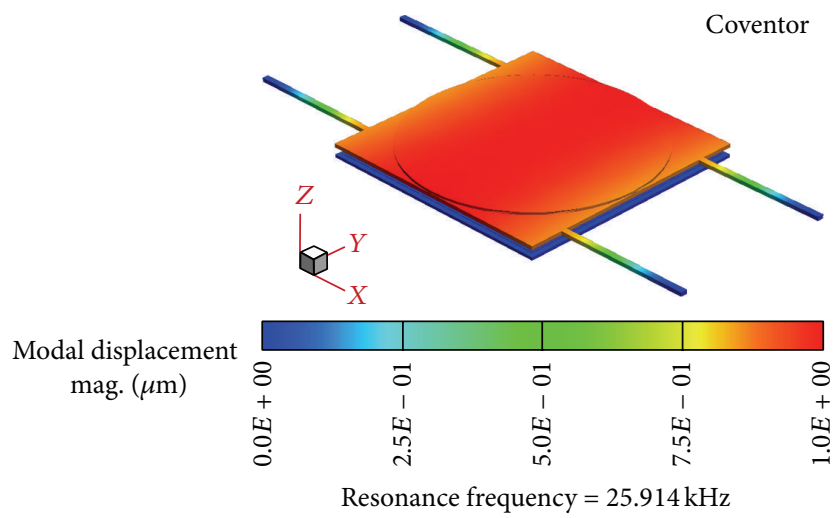

(c)

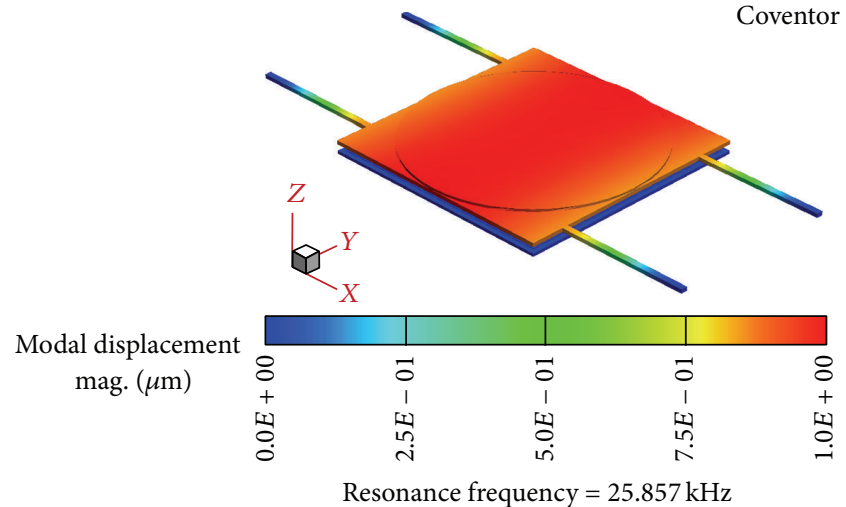

(b)

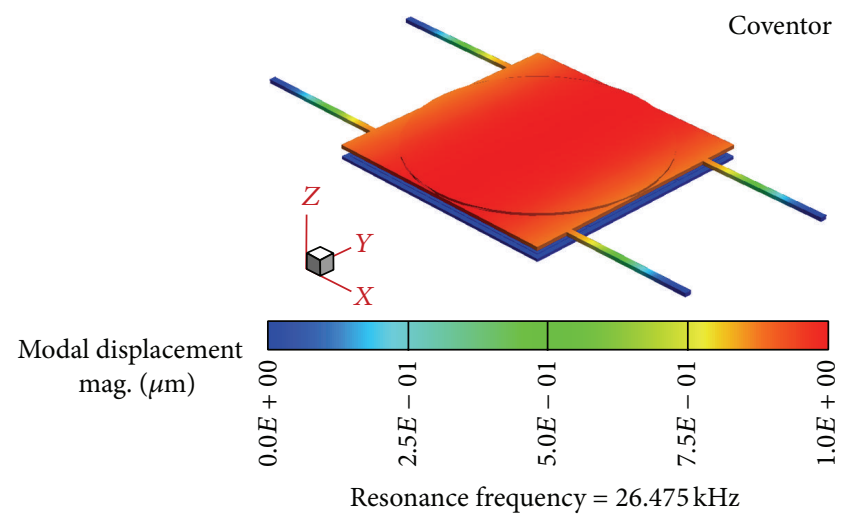

(d)

FiguRE 10: CoventorWare results showing resonance frequencies for the gap distances (a) $8 \mu \mathrm{m}$, (b) $9 \mu \mathrm{m}$, (c) $10 \mu \mathrm{m}$, and (d) $11 \mu \mathrm{m}$.

modal harmonic of the analyzer tool of the CoventorWare 2008 was used. The boundary conditions were set by fixing the device in the anchor points and applying the numerical damping. Loads equivalent to the electrostatic forces of 29.63, $40.329,48.98,56.019,82.305$, and 85.63 and $97.95 \mu \mathrm{N}$ for the gaps $5,6,7,8,9,10$, and $11 \mu \mathrm{m}$, respectively, were applied. The modal harmonic was studied in a wide range of frequencies of the driving force ranging from $100 \mathrm{~Hz}$ to $100 \mathrm{kHz}$. Figure 11 shows the simulated and modeled displacements versus the frequency of the driving force for all the gaps.
Figure 11 confirms that the device is overdamped when the gap distance is $5 \mu \mathrm{m}$ and heavily damped when the gap is $6 \mu \mathrm{m}$. Thus there is no clear peak of a resonance response at these two gaps. The damping is reduced when the gap is $7 \mu \mathrm{m}$; hence the peak response started to appear. By increasing the gap distance further to $8 \mu \mathrm{m}$ the damping is reduced further and as a result the peak displacement will get higher. The graphs for the rest of the gaps $(9,10$, and $11 \mu \mathrm{m})$ are not shown in this paper. However, they were found to follow the same trend shown by gap $8 \mu \mathrm{m}$ with higher displacements. The 


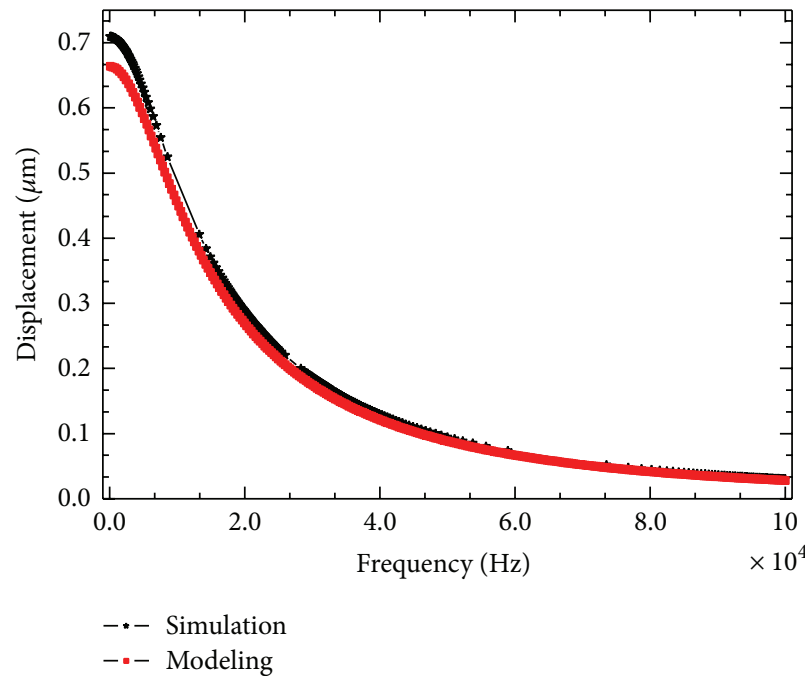

(a)

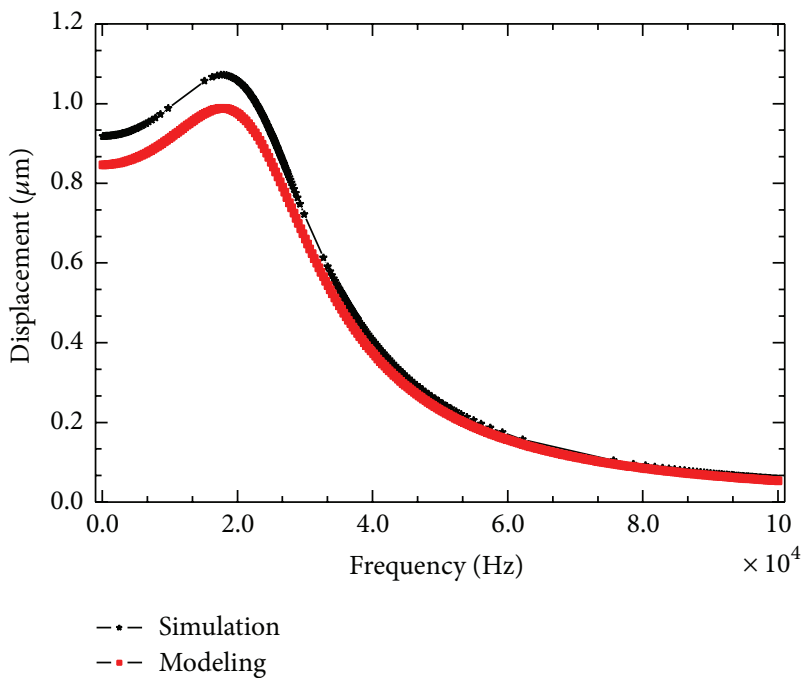

(c)

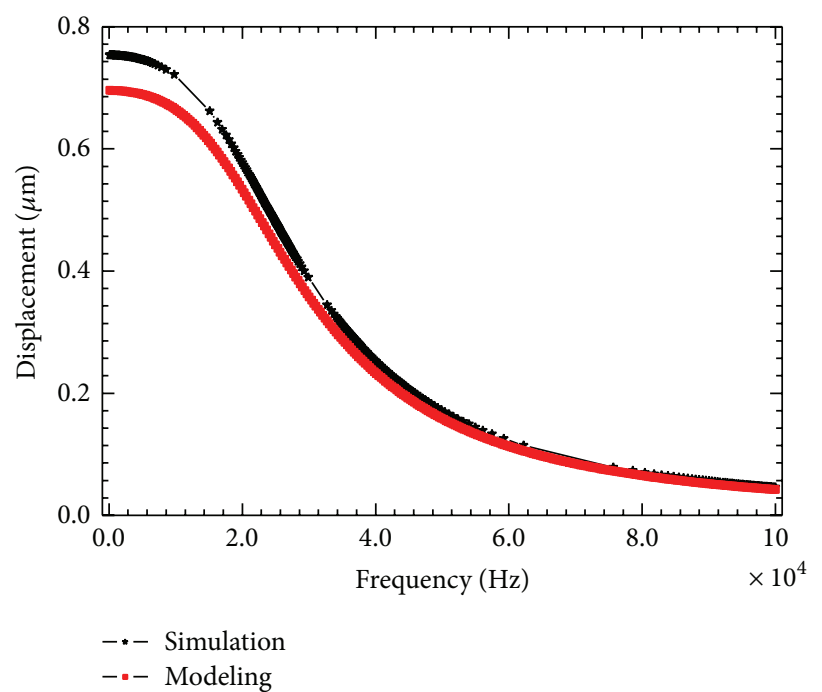

(b)

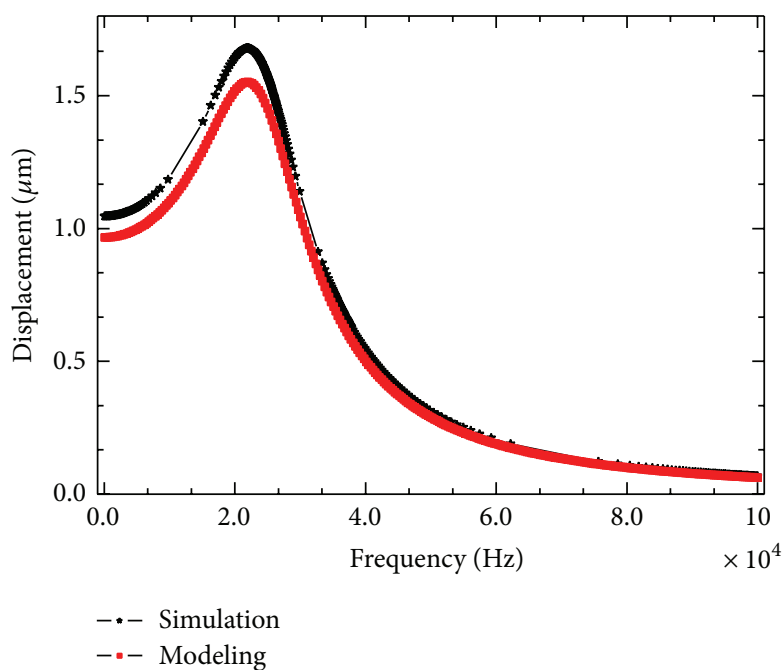

(d)

Figure 11: Modeled and simulated displacements for the gap distances (a) $5 \mu \mathrm{m}$, (b) $6 \mu \mathrm{m}$, (c) $7 \mu \mathrm{m}$, and (d) $8 \mu \mathrm{m}$.

simulated displacements for all the gaps are slightly higher compared to the modeled displacements. The percentage differences between the modeled and simulated displacements for the gaps of $5 \mu \mathrm{m}$ and $6 \mu \mathrm{m}$ were found to be in the range of 9.1-6.6\% and $9.5-7.6 \%$, respectively, in the studied range of the driving frequency. For the gaps of 7, 8, 9, 10, and $11 \mu \mathrm{m}$ the percentage difference between the simulated and modeled displacements at the peak response was found to be $10.6 \%$, $11.11 \%, 13.6 \%, 12.75 \%$, and $16.6 \%$, respectively.

\section{Discussion}

Due to the high squeeze film damping that associated with the initial gaps of $5 \mu \mathrm{m}$ and $6 \mu \mathrm{m}$ between the rotor and stator plates, the device is not behaving as a resonator in this case, and hence these two gaps were not included in the study of resonance frequency change. However, due to low actuation voltages for $5 \mu \mathrm{m}$ and $6 \mu \mathrm{m}$ compared to the higher gaps the change in the amplitude was proposed to investigate the possibility of operating the device using these two initial gaps. To study the amplitude change the rotor plate of the device is driven with a constant force and frequency and the amplitude shift is observed when the mass changes rather than the resonance frequency shift that associated with the resonators. It is believed that adding extra mass to a device driven with a constant force and frequency will lead to a decrease in the displacement amplitude as shown in (18). The mass sensitivity $(\mu \mathrm{m} / \mathrm{pg})$ for the different initial gaps was found using (21). The polymer coating thickness was fixed to $4 \mu \mathrm{m}$ thickness with a radius of $188 \mu \mathrm{m}$. Electrostatic forces of 29.63, 40.329, $48.98,56.019,82.305,85.63$, and $97.95 \mu \mathrm{N}$ were taken for the gaps $5,6,7,8,9,10$, and $11 \mu \mathrm{m}$, respectively. Those forces were selected to be far less compared to the forces equivalent to the pull-in voltages for the corresponding gaps. Wide range of frequencies for the driving force ranging from $100 \mathrm{~Hz}$ to 


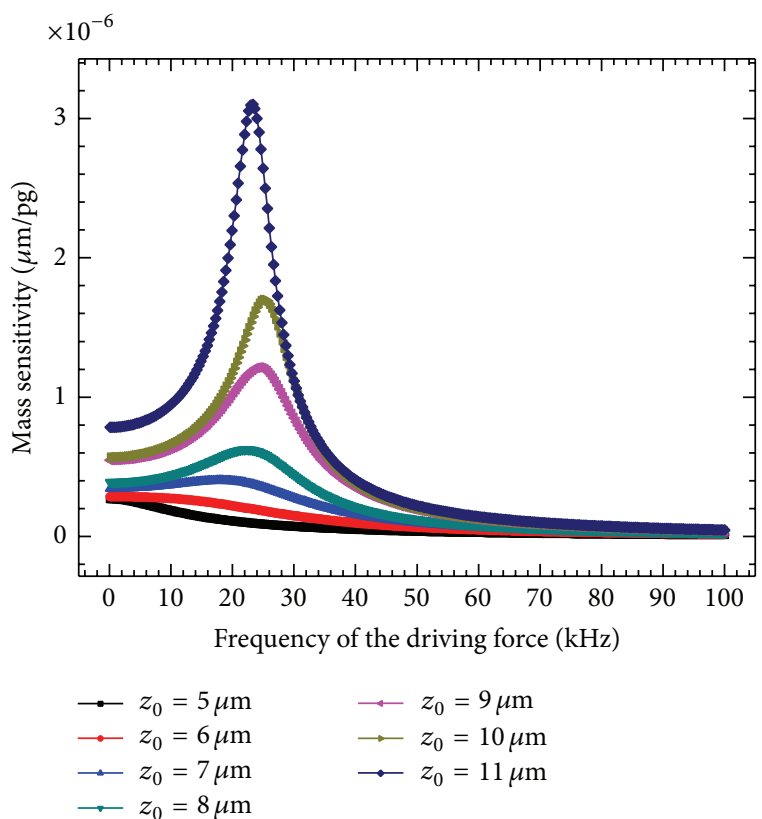

(a)

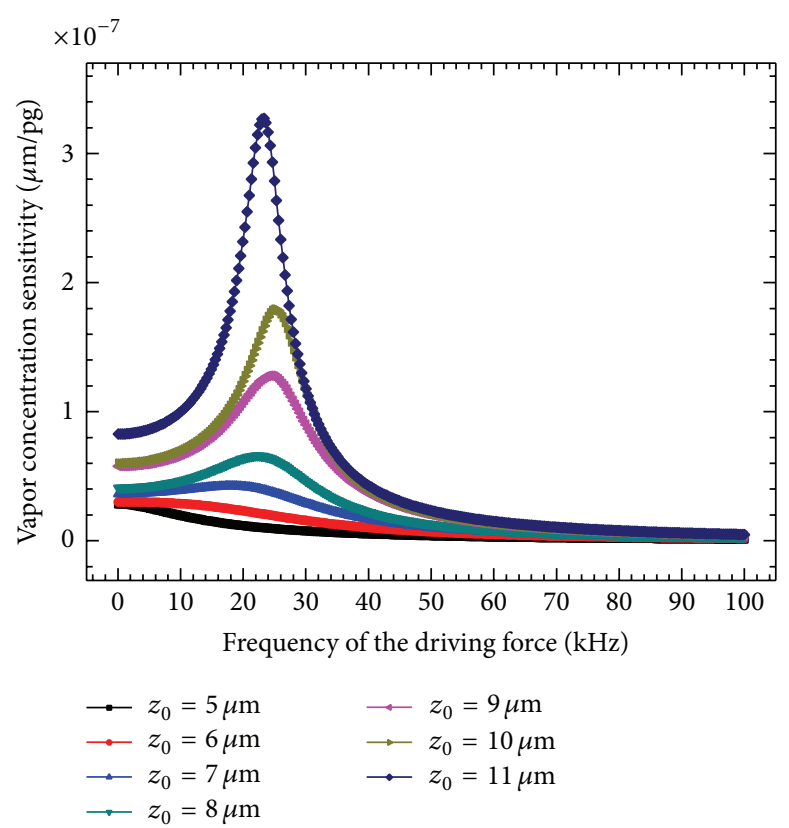

(b)

FIGURE 12: Plot of the frequency of the driving force versus (a) mass sensitivity and (b) vapor concentration sensitivity of the device of different initial gaps at $4 \mu \mathrm{m}$ polymer coating thickness.

$100 \mathrm{kHz}$ was chosen to determine the optimum frequency which gives the highest mass and vapor concentration sensitivity for each initial gap. Figure 12 shows the mass sensitivity and the vapor concentration sensitivity of the device for all the gaps.

As shown in Figure 12(a) the mass sensitivity $(\mathrm{pm} / \mathrm{pg}$ ) for the higher gaps ( $z_{0}=7 \mu \mathrm{m}$ and above) has higher values compared to the lower gaps $\left(z_{0}=5 \mu \mathrm{m}\right.$ and $\left.6 \mu \mathrm{m}\right)$. The maximum mass sensitivity of the device for the initial gaps of $7,8,9,10$, and $11 \mu \mathrm{m}$ was found to be $0.40,0.62,1.21$, 1.7 , and $2.46 \mathrm{pm} / \mathrm{pg}$ at frequencies of $17.989 \mathrm{kHz}, 22.345 \mathrm{kHz}$, $24.384 \mathrm{kHz}, 25.155 \mathrm{kHz}$, and $26.056 \mathrm{kHz}$, respectively. It is clear from (20) that the mass sensitivity is linearly related to the displacement and inversely related to the mass of the device. For the damping dominated gaps $\left(z_{0}=5 \mu \mathrm{m}\right.$ and $6 \mu \mathrm{m}$ ) there was no peak response observed, and the mass sensitivity decreases from $0.27 \mathrm{pm} / \mathrm{pg}$ and $0.29 \mathrm{pm} / \mathrm{pg}$, respectively, at $100 \mathrm{~Hz}$ to $0.011 \mathrm{pm} / \mathrm{pg}$ and $0.018 \mathrm{pm} / \mathrm{pg}$, respectively, at $100 \mathrm{kHz}$. This change is considerably small compared to the change observed in the higher gaps. For the larger gaps the mass sensitivity has a peak response at the resonance frequency of the device at those gaps and decreases when the frequency of the driving force is lower or higher than the resonance frequency of the device.

The vapor concentration sensitivity ( $\mathrm{pm} / \mathrm{ppm}$ ) follows the same trend as the mass sensitivity as shown in Figure 12(b). For the higher gaps $\left(z_{0}=7 \mu \mathrm{m}\right.$ and above) and due to the less damping there is a maximum peak of the vapor concentration sensitivity which is at the resonance. The maximum vapor concentration sensitivity for $7,8,9,10$, and $11 \mu \mathrm{m}$ was found to be $0.042,0.066,0.13,0.18$, and $0.26 \mathrm{pm} / \mathrm{ppm}$ at the frequencies of $17.989 \mathrm{kHz}, 22.345 \mathrm{kHz}$,
$24.384,25.155 \mathrm{kHz}$, and $26.056 \mathrm{kHz}$, respectively. As was observed for the mass sensitivity, the vapor concentration sensitivity for the damping dominated gaps $\left(z_{0}=5 \mu \mathrm{m}\right.$ and $6 \mu \mathrm{m})$ has no peak response. However, it decreases from $0.029 \mathrm{pm} / \mathrm{ppm}$ and $0.030 \mathrm{pm} / \mathrm{ppm}$, respectively, at $100 \mathrm{~Hz}$ to $0.0012 \mathrm{pm} / \mathrm{ppm}$ and $0.0019 \mathrm{pm} / \mathrm{ppm}$, respectively, at $100 \mathrm{kHz}$.

The change in the amplitude of the device driven with a constant force and frequency is very small and it is in the range of pico- to subpicrometer as shown above for all the given initial gaps. This change is very hard to be detected by the embedded piezoresistors or the sensing capacitor to get readable output voltage without using of very high sensitivity measurement instruments.

\section{Conclusion}

The electrostatically actuated and capacitively sensed CMOSMEMS device was modeled and simulated using a FEA simulation tool for acetone vapor detection in exhaled breath for noninvasive screening of diabetes. The resonator was modeled for different initial gaps $(5,6,7,8,9,10$, and $11 \mu \mathrm{m})$ between the stator and the rotor plates, with a different chitosan polymer coating thicknesses in a range of $1-20 \mu \mathrm{m}$. The device was found to be heavily damped for two initial gaps of $5 \mu \mathrm{m}$ and $6 \mu \mathrm{m}$. For the $5 \mu \mathrm{m}$ initial gap it was found to be overdamped and depending on the polymer coating thickness $(1-10 \mu \mathrm{m})$ the damping ratio was found to be in the range of 1.44-1.2. For the initial gap of $6 \mu \mathrm{m}$ the device was found to have damping ratio of $0.8-0.7$ for the given polymer coating thickness of $1-10 \mu \mathrm{m}$. For the two mentioned gaps the device does not behave as a resonator and hence it cannot be used for mass detection based on frequency shift. 
Increasing the initial gap until $11 \mu \mathrm{m}$ was found to decrease the squeeze damping effect and improves the performance of the device on one hand; however on the other hand increasing the gap was found to increase the required actuation voltages.

The resonance frequency, mass sensitivity, vapor concentration sensitivity, quality factor, and detection limit of the device for the gaps of $7,8,9,10$, and $11 \mu \mathrm{m}$ were found for the different polymer coating thicknesses. There was a good agreement within an accepted error (5.3\%) between the modeled and simulated frequencies from CoventorWare 2008 software. The vapor concentration sensitivity and the limit of detection were found to increase with increasing the polymer coating thickness. The minimum coating thickness of chitosan required to detect the minimum acetone vapor concentration $(1.8 \mathrm{ppm})$ in the exhaled breath of diabetic subjects was found to be $4 \mu \mathrm{m}$ for the initial gaps of 9 , 10 , and $11 \mu \mathrm{m}$, while for the gaps of $7 \mu \mathrm{m}$ and $8 \mu \mathrm{m}$ at least 5-7 $\mu \mathrm{m}$ coating thickness is needed to detect the same concentration level. It was found that the polymer coating thickness has the major effect on the sensor sensitivity and the detection limit. Although as smaller coating thickness as $4 \mu \mathrm{m}$ is sufficient to detect acetone vapor in the EB of the diabetic patients, up to $20 \mu \mathrm{m}$ thickness is recommended to detect down to $0.4 \mathrm{ppm}$ acetone concentration for the normal people.

Due to the high squeeze film damping associated with the $5 \mu \mathrm{m}$ and $6 \mu \mathrm{m}$ initial gaps there was no peak response in the displacements observed to detect the corresponding frequency shift. Therefore, the amplitude shift detection was proposed and studied to investigate the possibility of using all the gaps including $5 \mu \mathrm{m}$ and $6 \mu \mathrm{m}$. Wide range of driving force frequency from $100 \mathrm{~Hz}$ to $100 \mathrm{kHz}$ was used. For the studied range the device was found to give vapor concentration sensitivity of $0.042,0.066,0.130,0.180$, and 0.260 picometers/part per million $(\mathrm{pm} / \mathrm{ppm})$, at the frequencies of $17.989 \mathrm{kHz}, 22.345 \mathrm{kHz}, 24.384,25.155 \mathrm{kHz}$, and $26.056 \mathrm{kHz}$, respectively, for the initial gaps of 7, 8, 9, 10, and $11 \mu \mathrm{m}$, respectively. For the damping dominated gaps $\left(z_{0}\right.$ $=5 \mu \mathrm{m}$ and $6 \mu \mathrm{m})$ and because there was no peak response observed the vapor concentration sensitivity was found to decrease from $0.029 \mathrm{pm} / \mathrm{ppm}$ and $0.030 \mathrm{pm} / \mathrm{ppm}$, respectively, at $100 \mathrm{~Hz}$ of the driving frequency to $0.0012 \mathrm{pm} / \mathrm{ppm}$ and $0.0019 \mathrm{pm} / \mathrm{ppm}$, respectively, at $100 \mathrm{kHz}$ of the driving frequency.

\section{Competing Interests}

The authors declare that they have no competing interests.

\section{Acknowledgments}

The authors of this paper are grateful to Universiti Teknologi PETRONAS for providing the facilities. In addition, the authors acknowledge Ministry of Higher Education (MOHE), Malaysia, for the financial support under the Fundamental Research Grant Scheme (FRGS).

\section{References}

[1] C. Turner, C. Walton, S. Hoashi, and M. Evans, "Breath acetone concentration decreases with blood glucose concentration in type I diabetes mellitus patients during hypoglycaemic clamps," Journal of Breath Research, vol. 3, no. 4, Article ID 046004, 2009.

[2] C. Deng, J. Zhang, X. Yu, W. Zhang, and X. Zhang, "Determination of acetone in human breath by gas chromatographymass spectrometry and solid-phase microextraction with onfiber derivatization," Journal of Chromatography B: Analytical Technologies in the Biomedical and Life Sciences, vol. 810, no. 2, pp. 269-275, 2004.

[3] A. Reyes-Reyes, R. C. Horsten, H. P. Urbach, and N. Bhattacharya, "Study of the exhaled acetone in Type 1 diabetes using quantum cascade laser spectroscopy," Analytical Chemistry, vol. 87, no. 1, pp. 507-512, 2015.

[4] S.-J. Choi, I. Lee, B.-H. Jang et al., "Selective diagnosis of diabetes using Pt-functionalized $\mathrm{WO}_{3}$ hemitube networks as a sensing layer of acetone in exhaled breath," Analytical Chemistry, vol. 85, no. 3, pp. 1792-1796, 2013.

[5] M. Righettoni, A. Tricoli, and S. E. Pratsinis, "Si: $\mathrm{WO}_{3}$ sensors for highly selective detection of acetone for easy diagnosis of diabetes by breath analysis," Analytical Chemistry, vol. 82, no. 9, pp. 3581-3587, 2010.

[6] D. Guo, D. Zhang, N. Li, L. Zhang, and J. Yang, "A novel breath analysis system based on electronic olfaction," IEEE Transactions on Biomedical Engineering, vol. 57, no. 11, pp. 27532763, 2010.

[7] K.-W. Kao, M.-C. Hsu, Y.-H. Chang, S. Gwo, and J. Andrew Yeh, "A Sub-ppm acetone gas sensor for diabetes detection using $10 \mathrm{~nm}$ thick ultrathin InN FETs," Sensors, vol. 12, no. 6, pp. 71577168, 2012.

[8] C. Wang and P. Sahay, "Breath analysis using laser spectroscopic techniques: breath biomarkers, spectral fingerprints, and detection limits," Sensors, vol. 9, no. 10, pp. 8230-8262, 2009.

[9] L. Wang, K. Kalyanasundaram, M. Stanacevic, and P. Gouma, "Nanosensor device for breath acetone detection," Sensor Letters, vol. 8, no. 5, pp. 709-712, 2010.

[10] D. Hill and R. Binions, "Breath analysis for medical diagnosis," International Journal on Smart Sensing and Intelligent Systems, vol. 5, no. 2, pp. 401-440, 2012.

[11] S. V. Ryabtsev, A. V. Shaposhnick, A. N. Lukin, and E. P. Domashevskaya, "Application of semiconductor gas sensors for medical diagnostics," Sensors and Actuators B: Chemical, vol. 59, no. 1, pp. 26-29, 1999.

[12] L. Wang, A. Teleki, S. E. Pratsinis, and P. I. Gouma, "Ferroelectric WO3 nanoparticles for acetone selective detection," Chemistry of Materials, vol. 20, no. 15, pp. 4794-4796, 2008.

[13] N.-H. Kim, S.-J. Choi, S.-J. Kim et al., "Highly sensitive and selective acetone sensing performance of $\mathrm{WO}_{3}$ nanofibers functionalized by $\mathrm{Rh}_{2} \mathrm{O}_{3}$ nanoparticles," Sensors and Actuators B: Chemical, vol. 224, pp. 185-192, 2016.

[14] H. Ahn, Y. Wang, S. Hyun Jee, M. Park, Y. S. Yoon, and D.J. Kim, "Enhanced UV activation of electrochemically doped $\mathrm{Ni}$ in $\mathrm{ZnO}$ nanorods for room temperature acetone sensing," Chemical Physics Letters, vol. 511, no. 4-6, pp. 331-335, 2011.

[15] J.-S. Jang, S.-J. Kim, S.-J. Choi et al., “Thin-walled $\mathrm{SnO}_{2}$ nanotubes functionalized with $\mathrm{Pt}$ and $\mathrm{Au}$ catalysts via the protein templating route and their selective detection of acetone and hydrogen sulfide molecules," Nanoscale, vol. 7, no. 39, pp. 16417-16426, 2015. 
[16] P. A. Murade, V. S. Sangawar, G. N. Chaudhari, V. D. Kapse, and A. U. Bajpeyee, "Acetone gas-sensing performance of Sr-doped nanostructured $\mathrm{LaFeO}_{3}$ semiconductor prepared by citrate solgel route," Current Applied Physics, vol. 11, no. 3, pp. 451-456, 2011.

[17] J. Shin, S.-J. Choi, I. Lee et al., "Thin-wall assembled $\mathrm{SnO}_{2}$ fibers functionalized by catalytic Pt nanoparticles and their superior exhaled-breath-sensing properties for the diagnosis of diabetes," Advanced Functional Materials, vol. 23, no. 19, pp. 2357-2367, 2013.

[18] Z. Wang and C. Wang, "Is breath acetone a biomarker of diabetes? A historical review on breath acetone measurements," Journal of Breath Research, vol. 7, no. 3, Article ID 037109, 2013.

[19] G. F. Fine, L. M. Cavanagh, A. Afonja, and R. Binions, "Metal oxide semi-conductor gas sensors in environmental monitoring," Sensors, vol. 10, no. 6, pp. 5469-5502, 2010.

[20] G. Korotcenkov, "Metal oxides for solid-state gas sensors: what determines our choice?" Materials Science and Engineering B: Solid-State Materials for Advanced Technology, vol. 139, no. 1, pp. 1-23, 2007.

[21] D.-D. Lee, W.-Y. Chung, M.-S. Choi, and J.-M. Baek, "Lowpower micro gas sensor," Sensors and Actuators B: Chemical, vol. 33, no. 1-3, pp. 147-150, 1996.

[22] Q. Zhou, A. Sussman, J. Chang, J. Dong, A. Zettl, and W. Mickelson, "Fast response integrated MEMS microheaters for ultra low power gas detection," Sensors and Actuators A: Physical, vol. 223, pp. 67-75, 2015.

[23] V. Russino, F. Pieri, and P. Bruschi, "Design of an electronic oscillator for biosensing applications based on a MEMS resonator," in Proceedings of the 7th Conference on Ph.D. Research in Microelectronics and Electronics (PRIME '11), pp. 53-56, Trento, Italy, July 2011.

[24] A. A. S. Rabih, J. O. Dennis, M. H. Md Khir, and M. A. Abdullah, "Design, modeling and simulation of CMOS-MEMS resonator for biomedical application," in Proceedings of the 5th International Conference on Intelligent and Advanced Systems (ICIAS '14), pp. 1-6, Kuala Lumpur, Malaysia, June 2014.

[25] T. I. Nasution, I. Nainggolan, S. D. Hutagalung, K. R. Ahmad, and Z. A. Ahmad, "The sensing mechanism and detection of low concentration acetone using chitosan-based sensors," Sensors and Actuators B: Chemical, vol. 177, pp. 522-528, 2013.

[26] B. Bahreyni, Fabrication and Design of Resonant Microdevices, William Andrew, 2008.

[27] B. H. Karnopp and F. E. Fisher, "On the vibrations of overdamped systems," Journal of the Franklin Institute, vol. 327, no. 4, pp. 601-609, 1990.

[28] G. Takács and B. Rohal'-Ilkiv, Model Predictive Vibration Control: Efficient Constrained MPC Vibration Control for Lightly Damped Mechanical Structures, Springer, London, UK, 2012.

[29] C. Liu, Foundations of MEMS, Pearson Education, 2006.

[30] J.S. Pulskamp, Modeling, Fabrication, and Testing of Piezoelectric MEMS Vibrational Energy Reclamation Device, Army Research Labtotary, 2005.

[31] W. Wai-Chi, A. A. Azid, and B. Y. Majlis, "Formulation of stiffness constant and effective mass for a folded beam," Archives of Mechanics, vol. 62, no. 5, pp. 405-418, 2010.

[32] H. Sumali, "Squeeze-film damping in the free molecular regime: model validation and measurement on a MEMS," Journal of Micromechanics and Microengineering, vol. 17, no. 11, pp. 22312240, 2007.
[33] D. Lange, C. Hagleitner, O. Brand, and H. Baltes, "CMOS resonant beam gas sensing system with on-chip self excitation," in Proceedings of the 14th IEEE International Conference on Micro Electro Mechanical Systems (MEMS '01), pp. 547-552, Interlaken, Switzerland, January 2001.

[34] A. A. S. Rabih, J. O. Dennis, M. H. M. Khir, and M. A. Abdullah, "Mass detection using a macro-scale piezoelectric bimorph cantilever," in Proceedings of the IEEE International Conference on Smart Instrumentation, Measurement and Applications (ICSIMA '13), pp. 1-6, IEEE, Kuala Lumpur, Malaysia, November 2013.

[35] J. E.-Y. Lee, Silicon micromechanical resonators for measurements of mass and charge [Ph.D. thesis], Department of Engineering, University of Cambridge, Cambridge, UK, 2008.

[36] Y.-C. Li, M.-H. Ho, S.-J. Hung, M.-H. Chen, and M. S.-C. $\mathrm{Lu}$, "CMOS micromachined capacitive cantilevers for mass sensing," Journal of Micromechanics and Microengineering, vol. 16, no. 12, pp. 2659-2665, 2006.

[37] Y. Dong, W. Gao, Q. Zhou, Y. Zheng, and Z. You, "Characterization of the gas sensors based on polymer-coated resonant microcantilevers for the detection of volatile organic compounds," Analytica Chimica Acta, vol. 671, no. 1-2, pp. 85-91, 2010.

[38] M. I. Younis, MEMS Linear and Nonlinear Statics and Dynamics, vol. 20 of Microsystems, Springer, New York, NY, USA, 2011.

[39] S. Koev, Microcantilever biosensors with chitosan for the detection of nucleic acids and dopamine [Master of Science], Department of Electrical and Computer Engineering, University of Maryland, 2007.

[40] S. K. Rout, Physicochemical, functional, and spectroscopic analysis of crawfish chitin and chitosan as affected by process modification [Ph.D. thesis], The Department of Food Science, Louisiana State University and Agricultural and Mechanical College, 1994.

[41] P. P. Sahay, "Zinc oxide thin film gas sensor for detection of acetone," Journal of Materials Science, vol. 40, no. 16, pp. 43834385, 2005.

[42] M. Righettoni, A. Tricoli, S. Gass, A. Schmid, A. Amann, and S. E. Pratsinis, "Breath acetone monitoring by portable Si: $\mathrm{WO}_{3}$ gas sensors," Analytica Chimica Acta, vol. 738, pp. 69-75, 2012.

[43] A. Vomiero, S. Bianchi, E. Comini, G. Faglia, M. Ferroni, and G. Sberveglieri, "Controlled growth and sensing properties of $\mathrm{In}_{2} \mathrm{O}_{3}$ nanowires," Crystal Growth \& Design, vol. 7, no. 12, pp. 2500-2504, 2007.

[44] A. Teleki, S. E. Pratsinis, K. Kalyanasundaram, and P. I. Gouma, "Sensing of organic vapors by flame-made $\mathrm{TiO}_{2}$ nanoparticles," Sensors and Actuators B: Chemical, vol. 119, no. 2, pp. 683-690, 2006. 


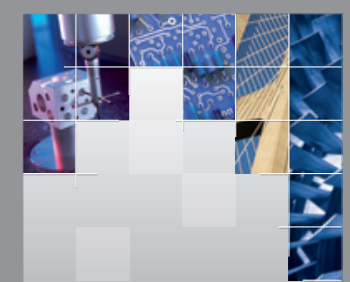

\section{Enfincering}
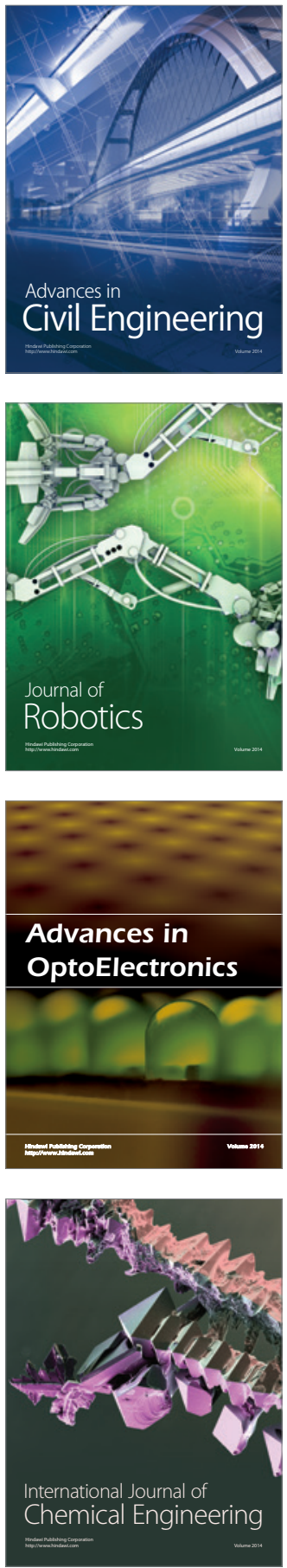

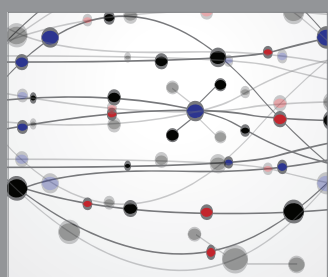

The Scientific World Journal

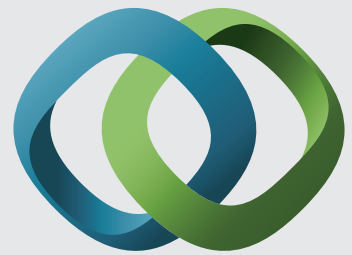

\section{Hindawi}

Submit your manuscripts at

http://www.hindawi.com
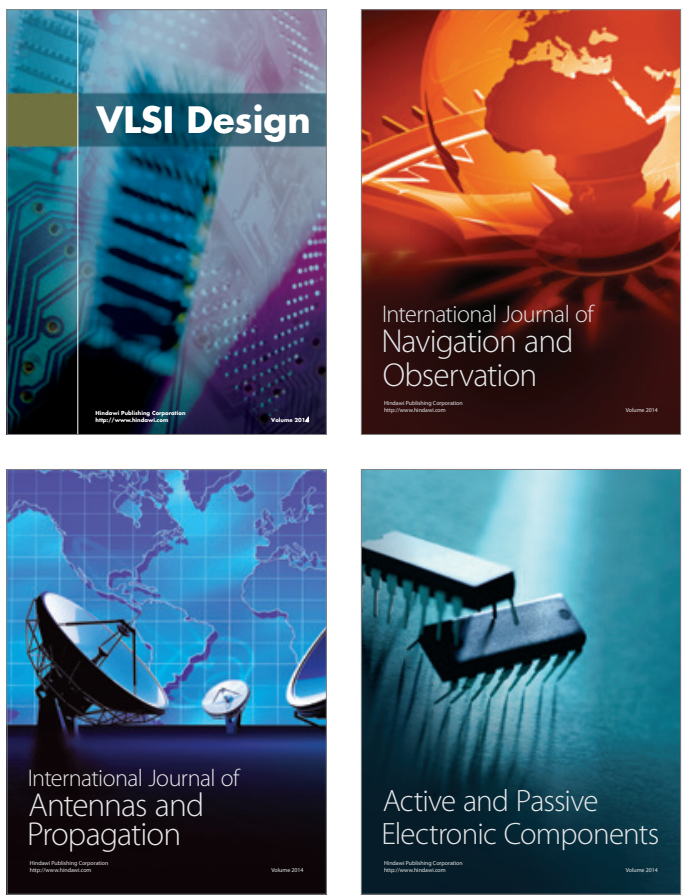
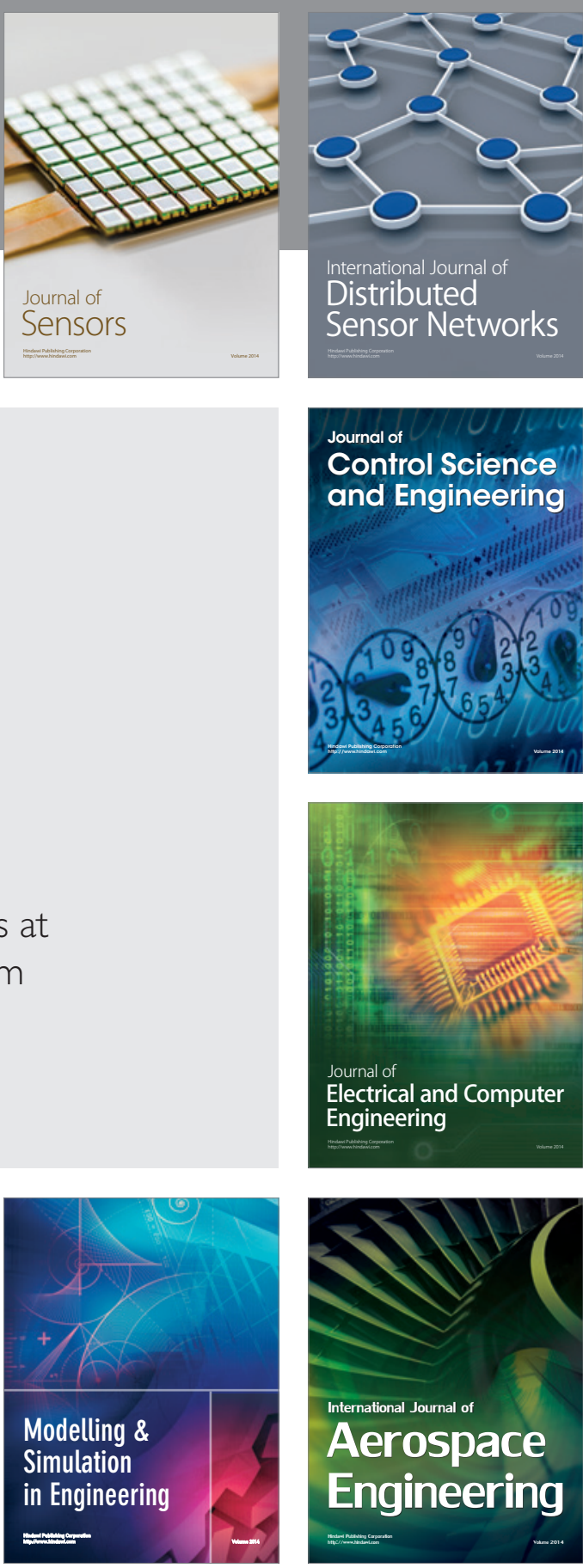

International Journal of

Distributed

Sensor Networks

Journal of

Control Science

and Engineering
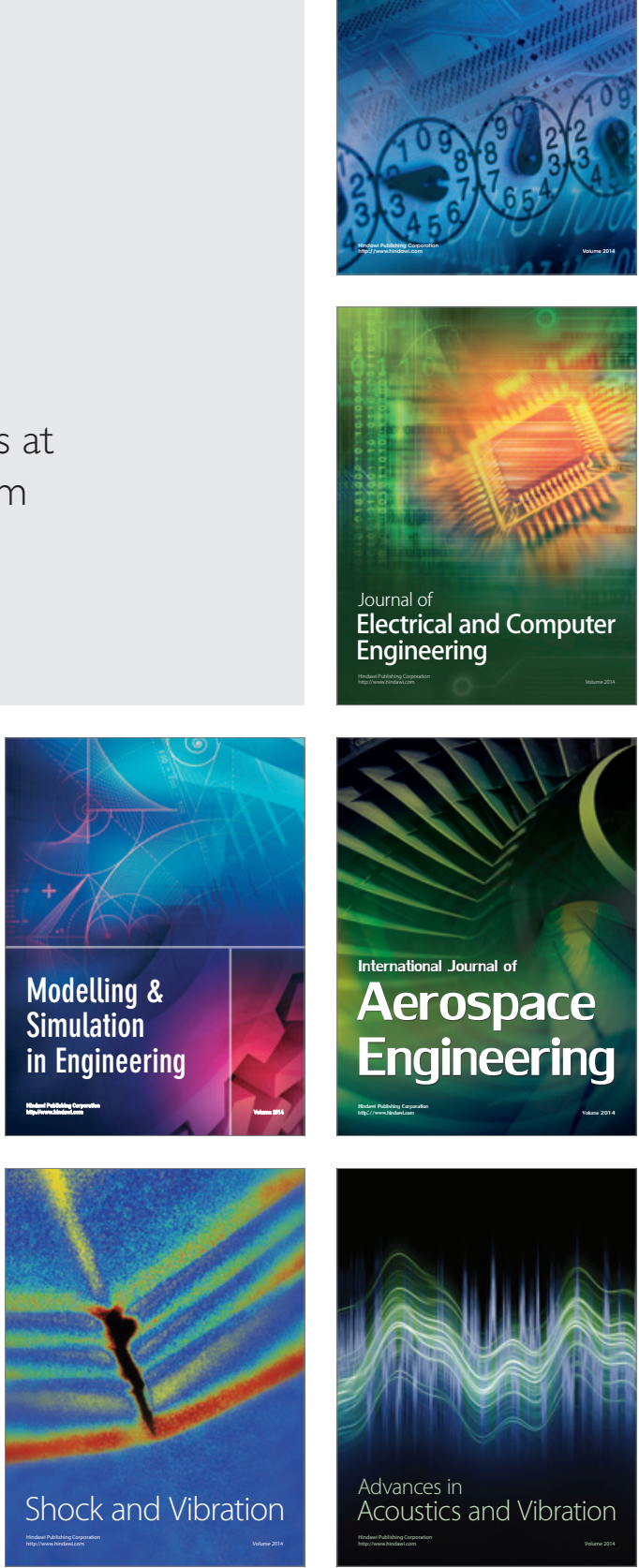